ARTICLE

Received 8 Apr 2016 | Accepted 14 Jun 2016 | Published 17 Aug 2016

DOI: $10.1038 /$ ncomms12223

OPEN

\title{
General low-temperature reaction pathway from precursors to monomers before nucleation of compound semiconductor nanocrystals
}

Kui Yu', Xiangyang Liu ${ }^{2}$, Ting $\mathrm{Qi}^{3}$, Huaqing Yang ${ }^{3}$, Dennis M. Whitfield ${ }^{2}$, Queena Y. Chen², Erik J. C. Huisman ${ }^{2}$ \& Changwei $\mathrm{Hu}^{1}$

Little is known about the molecular pathway to monomers of semiconductor nanocrystals. Here we report a general reaction pathway, which is based on hydrogen-mediated ligand loss for the precursor conversion to 'monomers' at low temperature before nucleation. We apply ${ }^{31} \mathrm{P}$ nuclear magnetic resonance spectroscopy to monitor the key phosphorous-containing products that evolve from $M X_{n}+E=\mathrm{PPh}_{2} \mathrm{H}+\mathrm{HY}$ mixtures, where $M X_{n}, E=\mathrm{PPh}_{2} \mathrm{H}$, and $\mathrm{HY}$ are metal precursors, chalcogenide precursors, and additives, respectively. Surprisingly, the phosphorous-containing products detected can be categorized into two groups, $\mathrm{Ph}_{2} \mathrm{P}-\mathrm{Y}$ and $\mathrm{Ph}_{2} \mathrm{P}(E)-Y$. On the basis of our experimental and theoretical results, we propose two competing pathways to the formation of $M_{2} E_{n}$ monomers, each of which is accompanied by one of the two products. Our study unravels the pathway of precursor evolution into $M_{2} E_{n}$ monomers, the stoichiometry of which directly correlates with the atomic composition of the final compound nanocrystals.

\footnotetext{
${ }^{1}$ Key Laboratory of Green Chemistry and Technology, Ministry of Education, College of Chemistry, Sichuan University, Chengdu 610065, China. ${ }^{2}$ Security and Disruptive Technologies, National Research Council Canada, Ottawa, Ontario, Canada K1A OR6. ${ }^{3}$ College of Chemical Engineering, Sichuan University, Chengdu 610065, China. Correspondence and requests for materials should be addressed to K.Y. (email: kuiyu@scu.edu.cn) or to H.Y. (email: huaqingyang@scu.edu.cn).
} 
C olloidal semiconductor nanocrystal (NC) quantum dots (QDs) with distinct properties and well-acknowledged potential in many applications such as light-emitting diodes $^{1,2}$, lasing ${ }^{3,4}$, photovoltaics ${ }^{5,6}$ and bio-labelling/imaging ${ }^{7-9}$ have been the focus of intense research ranging from fundamental science to applied technologies. For the past two decades, there have been significant efforts made to advance NC syntheses ${ }^{10-38}$. Mainly, the wet-chemical synthesis of colloidal metal chalcogenide NCs depends on the use of metal salts such as cadmium oleate $\left(\mathrm{Cd}(\mathrm{OA})_{2}\right.$ or $\left.\mathrm{Cd}\left(\mathrm{OOCC}_{17} \mathrm{H}_{33}\right)_{2}\right)$ and tri- $n$ octylphosphine chalcogenides $\left(E=\mathrm{P}\left(\mathrm{C}_{8} \mathrm{H}_{17}\right)_{3}\right.$ or $E$ TOP, $E=\mathrm{S}$, $\mathrm{Se}$, and $\mathrm{Te}$ ), together with beneficial additives in 1-octadecene (ODE) including diphenylphosphines ${ }^{13-19}$, primary alkyl amines $^{16,25-30,35,36}$, thiols ${ }^{22,29-31}$ and alcohols ${ }^{14,27,34}$.

A major advance in the NC synthesis occurred with the recognition that commercial tertiary phosphine TOP contains dioctylphosphine $\left(\mathrm{HP}\left(\mathrm{C}_{8} \mathrm{H}_{17}\right)_{2}\right.$, a secondary phosphine) that acts as an active impurity facilitating NC nucleation/growth but leading to low synthetic reproducibility (because of its varying amount from batch to batch $)^{13-15,23}$. It was first suggested ${ }^{15}$ and then experimentally demonstrated ${ }^{23}$ that the use of commercial diphenylphosphine $\left(\mathrm{HP}\left(\mathrm{C}_{6} \mathrm{H}_{5}\right)_{2}\right.$ or $\mathrm{HPPh}_{2}$, a secondary phosphine) resulted in an equilibrium of SeTOP $+\mathrm{HPPh}_{2} \rightleftharpoons$ $\mathrm{TOP}+\mathrm{Se}=\mathrm{PPh}_{2} \mathrm{H}$. Meanwhile, high metal-to-Se and low Se-toTOP feed ratios were found to shift the equilibrium to the right $^{23}$, which remarkably improved the NC synthesis with high particle yield and synthetic reproducibility at low reaction temperatures ${ }^{17-19,21,22,38} . E=\mathrm{PPh}_{2} \mathrm{H}$ is much more reactive than $E T O P{ }^{15,23}$. The use of $E \mathrm{TOP}+\mathrm{HPPh}_{2}$ leading to the $E$ precursor of $E=\mathrm{PPh}_{2} \mathrm{H}$ instead of $E \mathrm{TOP}$ has been shown to be beneficial for the synthesis of NCs such as PbSe (refs 17,18) and CdSeS (ref. 38), while the direct use of $E=\mathrm{PPh}_{2} \mathrm{H}$ (made from $\left.E+\mathrm{HPPh}_{2}\right)$ is preferable to the synthesis of NCs such as $\mathrm{ZnSe}$ (ref. 19), ZnSeS (ref. 21) and $\mathrm{CuInS}_{2}$ (ref. 22). With the large number of recipes developed, recent studies have demonstrated clearly that the control of precursor reactivity has a strong impact on the reproducibility, particle yield, and size and size distribution of the resulting NCs ${ }^{17-19,21,22,36-38}$. For example, the reactivity of thiourea precursors was shown to control the size, yield and batch-to-batch consistency of $\mathrm{PbS} \mathrm{NCs}^{37}$.

Generally, the current state-of-the-art in NC synthesis is principally empirical, with little insight into the stepwise pathway by which monomers are generated. There exists 'an induction period' before nucleation occurs, which was briefly addressed for CdSe from $\mathrm{CdX}_{2}+\mathrm{SePR}_{3} \quad(X=$ carboxylate and $R=$ alkane groups ref. 33). During the induction period, the consumption of $\mathrm{SeP}_{3}$ was visible, but NC absorbance did not appear. The consumption of $\mathrm{SeP} R_{3}$ was claimed to accumulate 'solutes' that may be composed of multiple monomer units; afterwards, nucleation took place. Accordingly, the formation of 'monomers' from precursors takes place at the beginning of the 'induction period'.

With the monomer in the form of $\mathrm{Cd}_{1} \mathrm{Se}_{1}$ instead of $\mathrm{Cd}_{2} \mathrm{Se}_{2}$, the pathway from precursors to $\mathrm{Cd}_{1} \mathrm{Se}_{1}$ monomers was recently documented for CdSe NCs in the presence of $\mathrm{C}_{18} \mathrm{H}_{35} \mathrm{NH}_{2}$ as one additive from the reaction of $\mathrm{Cd}(\mathrm{OA})_{2}+\mathrm{SeTOP}+\mathrm{HPPh}_{2}$. The P-containing products $\mathrm{Ph}_{2} \mathrm{P}-\mathrm{OOCC}_{17} \mathrm{H}_{33}(\mathbf{1 a}), \mathrm{Ph}_{2} \mathrm{P}-\mathrm{PPh}_{2}(\mathbf{1 b})$, $\mathrm{Ph}_{2} \mathrm{P}-\mathrm{NHC}_{18} \mathrm{H}_{35} \quad$ (1c) and $\mathrm{Ph}_{2} \mathrm{P}(\mathrm{Se})-\mathrm{NHC}_{18} \mathrm{H}_{35} \quad$ (2c) were detected, and the equilibrium of $\mathbf{1} \mathbf{c}+\mathrm{Se}=\mathrm{PPh}_{2} \mathrm{H} \rightleftharpoons \mathbf{2} \mathbf{c}+\mathrm{HPPh}_{2}$ was demonstrated ${ }^{25}$. Different NC systems are supposed to follow different reaction pathways to their monomers; for this seemingly obvious reason, we decided to investigate individual pathways from precursor evolution to monomers at low reaction temperatures in each of the reactions of $M X_{n}+n E=\mathrm{PPh}_{2} \mathrm{H}+\mathrm{HY}$, where $M=\mathrm{Cu}$ (I), Cd (II), Zn (II), Ge (II), $\mathrm{Pb}$ (II) and In (III), $E=\mathrm{S}$, Se and Te, and $\mathrm{HY}=\mathrm{RCOOH}, \mathrm{HPPh}_{2}, R \mathrm{NH}_{2}, R S H$ and
$R \mathrm{OH}$. The anion $X$ for the starting metal cations was chosen such that $M X_{n}$ is soluble under the reaction conditions and can often be a long-chain alkyl carboxylate or thiolate. This reaction system has proven to be practical for the synthesis of various NCs with high quality, enhanced reproducibility and yield $17-19,21,22,38$. However, the pathway from precursors to monomers of the reaction $M X_{n}+n E=\mathrm{PPh}_{2} \mathrm{H}+\mathrm{H} Y$ is perplexing to study because of the inevitable presence of $\mathrm{HX}$ and $\mathrm{HPPh}_{2}$ (as explained by the below equations 1-6).

Here, we present our study on the reaction pathway from precursors to $M_{2} E_{n}$ monomers for the reaction of $M X_{n}+$ $n E=\mathrm{PPh}_{2} \mathrm{H}+\mathrm{HY}$. Conclusively, various $\mathrm{P}$-containing compounds are detected for the metal $M=\mathrm{Cu}$ (I), Cd (II), Zn (II), $\mathrm{Ge}$ (II), $\mathrm{Pb}$ (II) and In (III) in combination with the chalcogen $E=\mathrm{S}$, Se and Te. Most importantly and surprisingly, we are able to categorize these $\mathrm{P}$-containing compounds into two groups of $\mathrm{Ph}_{2} \mathrm{P}-Y$ (1) and $\mathrm{Ph}_{2} \mathrm{P}(E)-Y$ (2), which are summarized in Supplementary Table 1 and Supplementary Note 1 (with $Y=-\mathrm{OOCC}_{17} \mathrm{H}_{33}(\mathbf{a}),-\mathrm{PPh}_{2}(\mathbf{b}),-\mathrm{NHC}_{18} \mathrm{H}_{35}(\mathbf{c}),-\mathrm{SC}_{12} \mathrm{H}_{25}(\mathbf{d})$ and $\left.-\mathrm{OC}_{12} \mathrm{H}_{25}(\mathbf{e})\right)$, together with the detailed information on their assignment that includes our calculation of ${ }^{31} \mathrm{P}$ NMR chemical shifts and a summary of the experimental information available in the literature. Accordingly, we propose two competing pathways leading to $M_{2} E_{n}$ monomers as illustrated by equations 1 and 2 (with further explanation in equations 3-6).

$$
2 M X_{n}+2 n E=\mathrm{PPh}_{2} \mathbf{H}^{\prime}+n \mathbf{H}^{\prime \prime} Y \rightarrow 2 n \mathbf{H}^{\prime} X+n E=\mathrm{PPh}_{2} \mathbf{H}^{\prime \prime}+M_{2} E_{n}+n \mathrm{Ph}_{2} \mathrm{P}-Y
$$

$2 M X_{n}+2 n E=\mathrm{PPh}_{2} \mathbf{H}^{\prime}+n \mathbf{H}^{\prime \prime} Y \rightarrow 2 n \mathbf{H}^{\prime} X+n \mathbf{H}^{\prime \prime} \mathrm{PPh}_{2}+M_{2} E_{n}+n \mathrm{Ph}_{2} \mathrm{P}(E)-\mathrm{Y}$

where $M=$ cation $\mathrm{Cu}(\mathrm{I}), \mathrm{Cd}(\mathrm{II}), \mathrm{Zn}$ (II), Ge (II), $\mathrm{Pb}$ (II) and In (III), $n=1,2$ and 3 of the oxidation state of monovalent, divalent and trivalent $M$, respectively, $X=$ anion (such as carboxylate $\left.\mathrm{C}_{17} \mathrm{H}_{33} \mathrm{COO}^{-}\right), E=\mathrm{S}$, Se and Te, and additive $\mathrm{HY}=R \mathrm{COOH}(\mathbf{a})$, $\mathrm{HPPh}_{2}(\mathbf{b}), R \mathrm{NH}_{2}$ (c), $R \mathrm{RH}$ (d) and $R \mathrm{OH}(\mathbf{e})$. A monomer in the form of $M_{2} E_{n}$ is proposed, which leads to NC nucleation followed by growth. The $\mathrm{H}$ atoms involved in the first and second H-mediated ligand loss steps are denoted as $\mathbf{H}^{\prime}$ and $\mathbf{H}^{\prime \prime}$, respectively. It is noteworthy that other secondary phosphines such as dicyclohexylphosphine $\left(\mathrm{HPCy}_{2}\right)$ leads to precursor $E=\mathrm{PCy}_{2} \mathrm{H}$ to start with; the correlation between the reactivity of $E=\mathrm{P} R_{2} \mathrm{H}$ (such as with $R=\mathrm{Ph}$ or $\mathrm{Cy}$ ) and the size of the resulting NCs will be the subject of another study. Our general stepwise pathway from precursor evolution to $M_{2} E_{n}$ monomers at low reaction temperatures should result in a much more in-depth fundamental understanding, which may advance the design and synthesis of colloidal semiconductor NCs and advance the realization of their potential.

\section{Results}

NMR study of various reaction systems. The reactions studied are presented in Fig. 1 for CdSe and Supplementary Figs 1-9 for $M$ (II) Se, Fig. 2 for CdS and Supplementary Figs 10-13 for CdS and ZnS, and Fig. 3 for CdTe and Supplementary Figs 14-21 for GeTe. Figure 4 is for $\mathrm{Cu}_{2} \mathrm{Se}, \mathrm{In}_{2} \mathrm{Se}_{3}$ and $\mathrm{CuInSe}_{2}$, and Supplementary Figs 22-23 are for $\mathrm{Cu}_{2} \mathrm{~S}, \mathrm{In}_{2} \mathrm{~S}_{3}$ and $\mathrm{CuInS}_{2}$. Figure 5 deals with $\left[\mathrm{Cd}\left(\mathrm{Se}_{2} \mathrm{PPh}_{2}\right)\right]_{2}(3)+\mathrm{Cd}(\mathrm{OA})_{2}+\mathrm{HY}$ for the demonstration of equation 2, which leads to $\mathrm{Cd}_{2} \mathrm{Se}_{2}+2$ as shown by Supplementary Fig. 25 and which is supported by Supplementary Fig. 24 with the reaction of $\left[\mathrm{Cd}\left(\mathrm{Se}_{2} \mathrm{PPh}_{2}\right)\right]_{2}$ (3) $+\mathrm{Cd}(\mathrm{OA})_{2}+\mathrm{HY}+\mathrm{HPPh}_{2}$. On the basis of our in situ ${ }^{31} \mathrm{P}$ NMR monitoring of a large number of reactions dealing with six metal cations $(M)$ and three chalcogens $(E)$ in the presence of the five types of $\mathrm{HY}$ additives, we propose a conceptual pathway 
(Fig. 6) that demonstrates the probable reactions from precursors to monomers. This distinct pathway starts with the coordination of $n E=\mathrm{PPh}_{2} \mathrm{H}$ molecules per $M X_{n}$, followed by the $\mathrm{H}$-mediated ligand loss of $n \mathrm{HX}$ molecules to result in one $M\left(E \mathrm{PPh}_{2}\right)_{n}(\mathbf{A})$. Afterwards, A undergoes dimerization to $\mathbf{D}$ that reacts with $\mathrm{HY}$ to $\mathbf{E}$ and/or $\mathbf{F}$, or reacts with $\mathrm{HY}$ leading to $\mathbf{B}$ and/or $\mathbf{C}$ that undergoes dimerization to $\mathbf{E}$ and/or $\mathbf{F}$, respectively. $M_{2} E_{n}$ and $\mathbf{1}$ are then produced from $\mathbf{E}$ (equation 1), while $M_{2} E_{n}$ and $\mathbf{2}$ from $\mathbf{F}$ (equation 2). Metathesis equilibria are involved, in which there are reversible exchanges of small ligand molecules, $\mathrm{HPPh}_{2}$, $E=\mathrm{HPPh}_{2}$ and $\mathrm{HY}$ (around metal chalcogenide centres, such as $\mathbf{D}+\mathrm{H} Y \rightleftharpoons \mathbf{E}+E=\mathrm{PPh}_{2} \mathrm{H}$ and $\left.\mathbf{D}+\mathrm{H} Y \rightleftharpoons \mathbf{F}+\mathrm{HPPh}_{2}\right)$, and chalcogenide exchange reactions such as $\mathbf{1}+\mathrm{Se}=\mathrm{PPh}_{2} \mathrm{H} \rightleftharpoons 2+$ $\mathrm{HPPh}_{2}$, which affect the detection of $\mathbf{1}, 2$ and $\mathrm{HPPh}_{2}$. The chalcogenide exchange equilibria were examined by density functional theory (DFT) shown in Supplementary Table 2 and Supplementary Note 2. Furthermore, we performed extensive DFT calculations for the probable isomers of the intermediates A-F shown in Fig. 6; therefore, we are able to elucidate further the pathway we proposed in Fig. 7, in which the probable isomers with detailed bonding skeletons of each intermediate $\mathbf{A}-\mathbf{F}$ are illustrated, providing a much deeper understanding.

Figure 1 presents our ${ }^{31} \mathrm{P}$ NMR spectra collected from four representative mixtures of $\mathrm{Cd}(\mathrm{OA})_{2}+\mathrm{SeTOP}+\mathrm{HPPh}_{2}$ (a) and with the additional additives of oleylamine $\left(\mathrm{C}_{18} \mathrm{H}_{35} \mathrm{NH}_{2}, \mathbf{b}\right)$, dodecylthiol $\left(\mathrm{C}_{12} \mathrm{H}_{25} \mathrm{SH}, \mathbf{c}\right)$ and dodecylalcohol $\left(\mathrm{C}_{12} \mathrm{H}_{25} \mathrm{OH}, \mathbf{d}\right)$. It is $\mathrm{Se}=\mathrm{PPh}_{2} \mathrm{H}$ rather than SeTOP that reacts with $\mathrm{Cd}(\mathrm{OA})_{2}$ because of $\mathrm{SeTOP}+\mathrm{HPPh}_{2} \rightleftharpoons \mathrm{Se}=\mathrm{PPh}_{2} \mathrm{H}+\mathrm{TOP}$ (refs 15,23). The products 1a $\left(\mathrm{Ph}_{2} \mathrm{P}-\mathrm{OOCC}_{17} \mathrm{H}_{35}\right)$ and $\mathbf{1 b}\left(\mathrm{Ph}_{2} \mathrm{P}-\mathrm{PPh}_{2}\right)$ equilibrate via $\mathrm{Ph}_{2} \mathrm{P}-\mathrm{COOR}(\mathbf{1 a})+\mathrm{HPPh}_{2} \rightleftharpoons R \mathrm{COOH}+\mathrm{Ph}_{2} \mathrm{P}-$ $\mathrm{PPh}_{2}(\mathbf{1 b})$, which is weighted to the right at room temperature $(\mathrm{RT})^{21,24}$. The additional products of $2 \mathbf{a}\left(\mathrm{Ph}_{2} \mathrm{P}(\mathrm{Se})-\mathrm{OOCC}_{17} \mathrm{H}_{35}\right)$ and $\mathbf{2 b}\left(\mathrm{Ph}_{2} \mathrm{P}(\mathrm{Se})-\mathrm{PPh}_{2}\right)$ from the mixtures of $\mathrm{Cd}(\mathrm{OA})_{2}, \mathrm{Zn}(\mathrm{OA})_{2}$

a

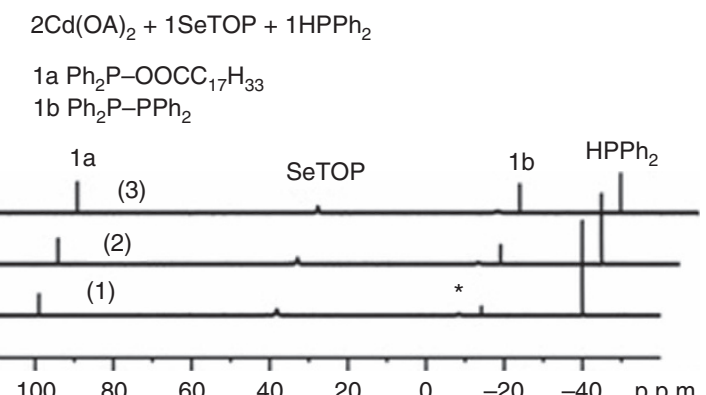

C

$2 \mathrm{Cd}(\mathrm{OA})_{2}+1 \mathrm{SeTOP}+1 \mathrm{HPPh}_{2}+2 \mathrm{C}_{12} \mathrm{H}_{25} \mathrm{SH}$

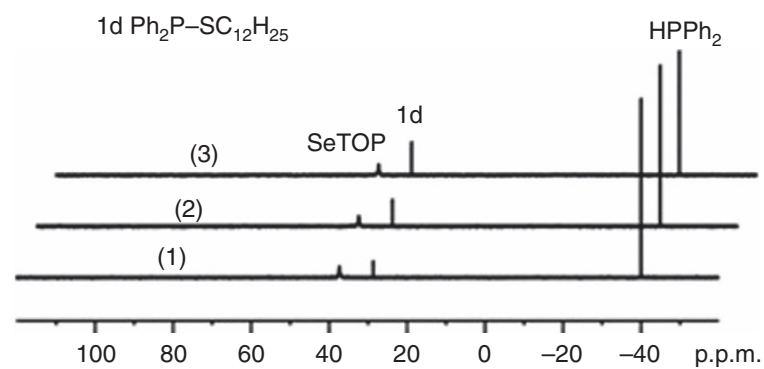

or $\mathrm{Ge}(\mathrm{OA})_{2}+\mathrm{Se}=\mathrm{PPh}_{2} \mathrm{H}$ are shown in Supplementary Figs 3-5. The addition of a primary amine $\mathrm{C}_{18} \mathrm{H}_{35} \mathrm{NH}_{2}$ to the mixture of Fig. 1a, as shown in Fig. 1b, resulted in additional 1c $\left(\mathrm{Ph}_{2} \mathrm{P}-\mathrm{NHC}_{18} \mathrm{H}_{35}\right)$ and $2 \mathrm{c}\left(\mathrm{Ph}_{2} \mathrm{P}(\mathrm{Se})-\mathrm{NHC}_{18} \mathrm{H}_{35}\right)$. The use of the thiol $\mathrm{C}_{12} \mathrm{H}_{25} \mathrm{SH}$ generated 1d $\left(\mathrm{Ph}_{2} \mathrm{P}-\mathrm{SC}_{12} \mathrm{H}_{25}\right)$ without the detection of $\mathbf{1 a}$ and $\mathbf{1 b}$ (Fig. 1c). Similarly, the use of the alcohol $\mathrm{C}_{12} \mathrm{H}_{25} \mathrm{OH}$ produced 1e $\left(\mathrm{Ph}_{2} \mathrm{P}-\mathrm{OC}_{12} \mathrm{H}_{25}\right)$ and $2 \mathrm{e}$ $\left(\mathrm{Ph}_{2} \mathrm{P}(\mathrm{Se})-\mathrm{OC}_{12} \mathrm{H}_{25}\right.$; Fig. 1d). The same P-containing compounds were observed from the mixtures with $\mathrm{Pb}(\mathrm{OA})_{2}$ replacing $\mathrm{Cd}(\mathrm{OA})_{2}$ (Supplementary Fig. 5), which strongly suggests that Compounds 1a-e $\left(\mathrm{Ph}_{2} \mathrm{P}-\mathrm{Y}\right)$ have their own similar pathways (for different $Y$ ), and Compounds 2a-e $\left(\mathrm{Ph}_{2} \mathrm{P}(\mathrm{Se})-Y\right)$ have their own similar pathways (for different $Y$ ). Thus, we propose that Compounds $\mathbf{1}$ and $\mathbf{2}$ follow two different paths for their formation from their own immediate precursors (Figs 1 and 2).

The temporal evolution of the absorption of growing CdSe NCs (shown in Supplementary Figs 6-7) suggests that the amount of additives, thiol $\mathrm{C}_{12} \mathrm{H}_{25} \mathrm{SH}$ or alcohol $\mathrm{C}_{12} \mathrm{H}_{25} \mathrm{OH}$ affects nucleation/growth, in addition to other experimental parameters such as the temperature and amount of $\mathrm{HPPh}_{2}$ used. Focusing on the identification of the reaction pathway before nucleation, the present study does not address the control of the size and size distribution, which could be affected by various experimental parameters including cation-to-anion feed molar ratios and the nature of $\mathrm{Se}=\mathrm{P} R_{2} \mathrm{H}$ as shown by Supplementary Figs 8 and 9. In addition, the size and size distribution of the CdSe NCs synthesized with SeTOP $+\mathrm{HPR}_{2}$ (dicyclohexylphosphine (or $\left.\mathrm{HPCy}_{2}\right)$ and $\mathrm{HPPh}_{2}$ ) are different from those with $\mathrm{Se}=\mathrm{PCy}_{2} \mathrm{H}$ and $\mathrm{Se}=\mathrm{PPh}_{2} \mathrm{H}$. Previously, the reaction of $\mathrm{Cd}(\mathrm{OA})_{2}+\mathrm{Se}=\mathrm{PCy}_{2} \mathrm{H}$ was reported to lead to Compound $\mathrm{Cy}_{2} \mathrm{P}-\mathrm{OOCC}_{17} \mathrm{H}_{33}$ (1a analogue) and $\mathrm{Cy}_{2} \mathrm{P}(\mathrm{Se})-\mathrm{OOCC}_{17} \mathrm{H}_{33} \quad(\mathbf{2 a} \text { analogue })^{24}$. Therefore, the present study on the general reaction pathway b

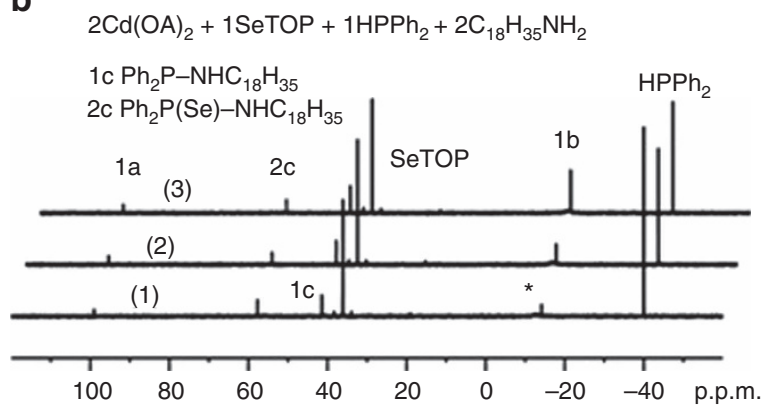

d

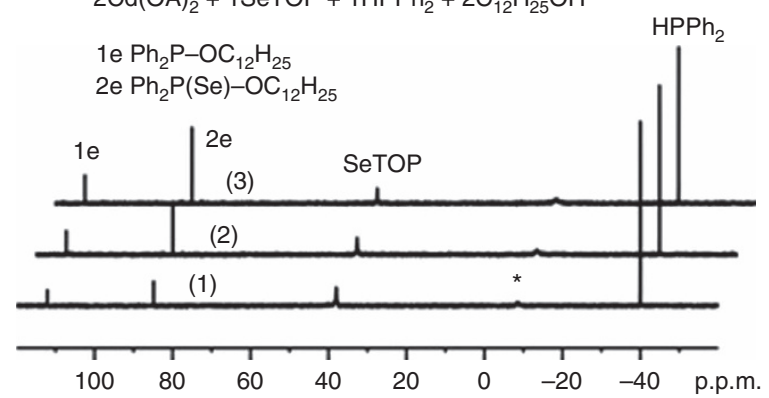

Figure 1 | ${ }^{31} \mathbf{P}$ NMR spectra of CdSe reaction mixtures with Se precursor. (a) $2 \mathrm{Cd}\left(\mathrm{OOCC}_{17} \mathrm{H}_{33}\right)_{2}+\mathrm{SeTOP}+\mathrm{HPPh}_{2}$. (b) $2 \mathrm{Cd}\left(\mathrm{OOCC} \text { 17 } \mathrm{H}_{33}\right)_{2}+\mathrm{SeTOP}+$ $\mathrm{HPPh}_{2}+2 \mathrm{C}_{18} \mathrm{H}_{35} \mathrm{NH}_{2}$. (c) $2 \mathrm{Cd}\left(\mathrm{OOCC}_{17} \mathrm{H}_{33}\right)_{2}+\mathrm{SeTOP}+\mathrm{HPPh}_{2}+2 \mathrm{C}_{12} \mathrm{H}_{25} \mathrm{SH}$. (d) $2 \mathrm{Cd}\left(\mathrm{OOCC}_{17} \mathrm{H}_{33}\right)_{2}+\mathrm{SeTOP}+\mathrm{HPPh} \mathrm{H}_{2}+2 \mathrm{C}_{12} \mathrm{H}_{25} \mathrm{OH}$. The experiments were performed at RT for 15 (1), 30 (2) and 60 min (3). The peak denoted with an asterisk $\left(^{\star}\right)$ is TOP complexed to Cd (ref. 23). Interestingly, the $\mathrm{P}$-containing products detected from the four reactions can be grouped into two product types, $\mathrm{Ph}_{2} \mathrm{P}-\mathrm{Y}(\mathbf{1})$ and $\mathrm{Ph}{ }_{2} \mathrm{P}(\mathrm{Se})-\mathrm{Y}(\mathbf{2})$. The slowest disappearance of SeTOP is with the use of amine, the trend of which is in agreement with our kinetics study (Supplementary Figs 28-31 and Supplementary Note 5) based on our putative pathway proposed (Fig. 6) and the consideration of constitutional isomers (Fig. 7). 
a

$$
\begin{array}{cr}
\text { 2Cd}(\mathrm{OA})_{2}+1 \mathrm{~S}=\mathrm{PPh}_{2} \mathrm{H} & \\
& 2 \mathrm{~b}^{\prime} \mathrm{Ph}_{2} \mathrm{P}(\mathrm{S})-\mathrm{PPh}_{2} \\
\text { 1a } \mathrm{Ph}_{2} \mathrm{P}-\mathrm{OOCC}{ }_{17} \mathrm{H}_{33} & 45 \text { p.p.m }\left(d, J_{\mathrm{P}-\mathrm{P}}=245 \mathrm{~Hz}\right) \\
& -14 \text { p.p.m }\left(d, J_{\mathrm{P}-\mathrm{P}}=245 \mathrm{~Hz}\right)
\end{array}
$$

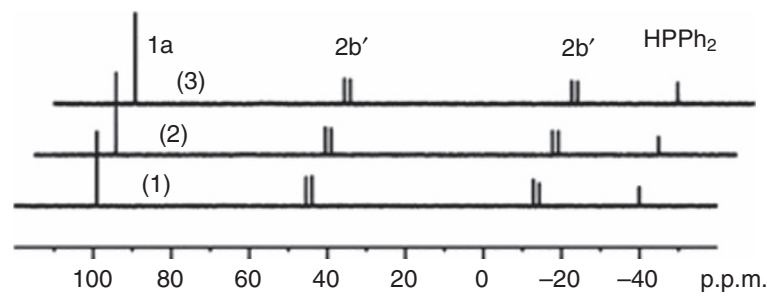

C

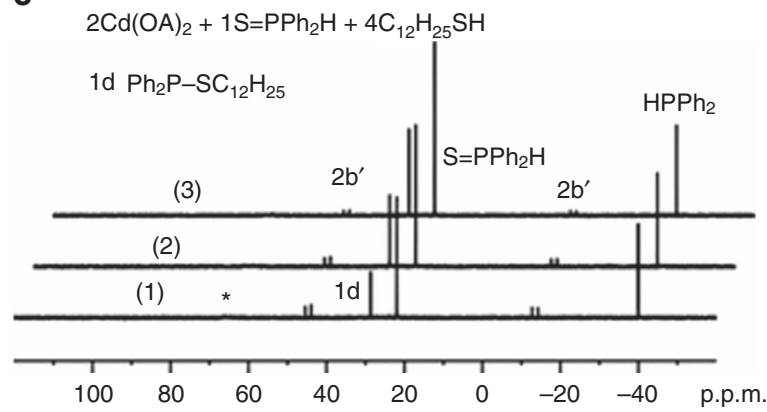

b

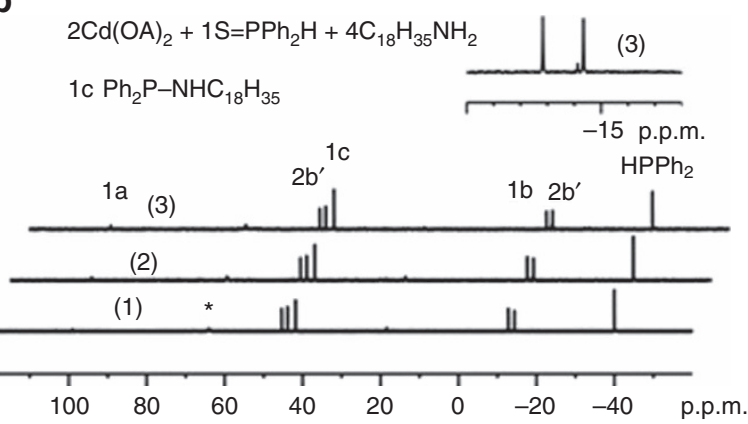

d

$2 \mathrm{Cd}(\mathrm{OA})_{2}+1 \mathrm{~S}=\mathrm{PPh}_{2} \mathrm{H}+4 \mathrm{C}_{12} \mathrm{H}_{25} \mathrm{OH}$

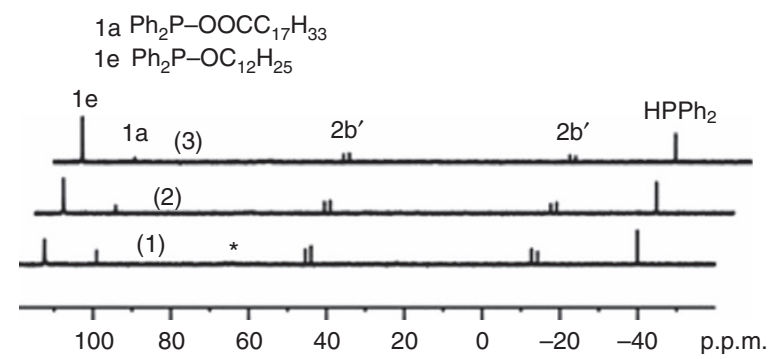

Figure $\left.2\right|^{31} \mathbf{P}$ NMR spectra of $\mathbf{C d S}$ reaction mixtures with $\mathbf{S}$ precursor. (a) $2 \mathrm{Cd}\left(\mathrm{OOCC}_{17} \mathrm{H}_{33}\right)_{2}+\mathrm{S}=\mathrm{PPh}_{2} \mathrm{H}$. $(\mathbf{b}) 2 \mathrm{Cd}\left(\mathrm{OOCC} 17 \mathrm{H}_{33}\right)_{2}+\mathrm{S}=\mathrm{PPh}_{2} \mathrm{H}+$ $4 \mathrm{C}_{18} \mathrm{H}_{35} \mathrm{NH}_{2}$. (c) $2 \mathrm{Cd}\left(\mathrm{OOCC}_{17} \mathrm{H}_{33}\right)_{2}+\mathrm{S}=\mathrm{PPh}_{2} \mathrm{H}+4 \mathrm{C}_{12} \mathrm{H}_{25} \mathrm{SH}$. The $1 \mathbf{d}-$ to $-\mathrm{S}=\mathrm{PPh}_{2} \mathrm{H}$ ratio increased from 0.28 (1), 0.36 (2) to 0.41 (3) is shown in Supplementary Fig. 2c. (d) $2 \mathrm{Cd}\left(\mathrm{OOCC}_{17} \mathrm{H}_{33}\right)_{2}+\mathrm{S}=\mathrm{PPh}_{2} \mathrm{H}+4 \mathrm{C}_{12} \mathrm{H}_{25} \mathrm{OH}$. The experiments were carried out at RT for 15 (1), 30 (2) and 60 min (3). The peak denoted with an asterisk $\left(^{\star}\right)$ is probably $\mathrm{Cd}\left(\mathrm{S}_{2} \mathrm{PPh}_{2}\right)_{2}$ (ref. 36$)$.

from precursors to $M_{2} E_{n}$ monomers before nucleation at low reaction temperatures should benefit the field by leading to a better understanding of the 'induction periods' to tailor, optimize and manipulate nucleation/growth, which offers finer control of the size and size distribution of NCs produced.

Figure 2 shows our ${ }^{31} \mathrm{P}$ NMR spectra collected from four representative mixtures of $\mathrm{Cd}(\mathrm{OA})_{2}+\mathrm{S}=\mathrm{PPh}_{2} \mathrm{H}$ (a) and with the additional additives of oleylamine $\left(\mathrm{C}_{18} \mathrm{H}_{35} \mathrm{NH}_{2}, \mathbf{b}\right)$, dodecylthiol $\left(\mathrm{C}_{12} \mathrm{H}_{25} \mathrm{SH}, \mathbf{c}\right)$ and dodecylalcohol $\left(\mathrm{C}_{12} \mathrm{H}_{25} \mathrm{OH}, \mathbf{d}\right)$. The chalcogenide $\mathrm{S}$ is generally less reactive than $\mathrm{Se}$ and Te under QD formation conditions ${ }^{10-12}$. Rather than employing an in situ generation of $\mathrm{Se}=\mathrm{PPh}_{2} \mathrm{H}$ (Fig. 1 and Supplementary Figs 1-9) or $\mathrm{Te}=\mathrm{PPh}_{2} \mathrm{H}$ (Fig. 3 and Supplementary Figs 14-21), the analogue $\mathrm{S}=\mathrm{PPh}_{2} \mathrm{H}$ is sufficiently stable to be used directly (Supplementary Figs $10-13)^{21,22}$. The P-containing products detected from the $\mathrm{S}=\mathrm{PPh}_{2} \mathrm{H}$-related reactions with $\mathrm{Cd}(\mathrm{OA})_{2}$ (without additional $\mathrm{HPPh}_{2}$ but with free $\mathrm{HPPh}_{2}$ present) are similar to other chalcogenide-related reactions (Figs 1 and 3). Again, the products from the four reactions (Fig. 2) are grouped into Compounds 1 and 2. For example, the products formed are elucidated as follows: 1a without an additive (Fig. 2a), 1a and 1c with an amine additive (Fig. 2b), 1d with a thiol additive (Fig. 2c) and 1e and 1a with an alcohol additive (Fig. 2d). The major difference between the $\mathrm{Cd}+\mathrm{S}$ reactions (Fig. 2) and the $\mathrm{Cd}+\mathrm{Se}$ reactions (Fig. 1) is the formation of $\mathbf{2} \mathbf{b}^{\prime}\left(\mathrm{Ph}_{2} \mathrm{P}(\mathrm{S})-\mathrm{PPh}_{2}\right)$ under all conditions. Compound $\mathbf{2} \mathbf{b}^{\prime}$ was also detected from a mixture of $\mathrm{Zn}(\mathrm{OA})_{2}+\mathrm{S}=\mathrm{PPh}_{2} \mathrm{H}$ shown in Supplementary Figs 10-12.

TeTOP is much more reactive than SeTOP and STOP in QD engineering ${ }^{10-12}$. Under the reaction conditions, this fact is readily discernible, as TeTOP (Supplementary Fig. 14) reacts completely when the first spectrum (1) of the each reaction shown in Fig. 3 was collected. Again, the products 1a (Fig. 3a), 1c (together with 1a, in the presence of amine Fig. 3b), 1d (in the presence of thiol Fig. 3c) and 1e (in the presence of alcohol Fig. 3d) were detected in addition to $\mathbf{1 b}$. The same P-containing products were detected from the $\mathrm{Ge}(\mathrm{OA})_{2}+\mathrm{TeTOP}+\mathrm{HPPh}_{2}+$ HY reactions (Supplementary Fig. 19). As shown in Supplementary Figs 15-17, the amount of $\mathrm{HPPh}_{2}$ used affects the ratio of $\mathbf{1 a}$ and $\mathbf{1 b}$ detected in the mixture of $\mathrm{Cd}(\mathrm{OA})_{2}+\mathrm{TeTOP}+\mathrm{HPPh}_{2}$ : the more $\mathrm{HPPh}_{2}$ is used, the more diphosphine compound $\mathbf{1 b}$ is detected, the trend of which is similar to what was reported for CdSe because of the equilibrium of $\mathrm{Ph}_{2} \mathrm{P}-\mathrm{COOR}$ (1a) $+\mathrm{HPPh}_{2} \rightleftharpoons \mathrm{RCOOH}+\mathrm{Ph}_{2} \mathrm{P}-\mathrm{PPh}_{2}$ (1) being weighted towards the right at $\mathrm{RT}^{21,24}$. Notably under these conditions, no Compound $2\left(\mathrm{Ph}_{2} \mathrm{P}(\mathrm{Te})-Y\right)$ was observed. The Te-P bond strength is lower than that of $\mathrm{Se}-\mathrm{P}$ or $\mathrm{S}-\mathrm{P}$ and, thus, $\mathrm{Ph}_{2} \mathrm{P}(\mathrm{Te})-Y$ might be too reactive to be detected.

For the S, Se and Te chalcogenide series with Cd (II) under all examined conditions (Figs 1-3), $\mathrm{Ph}_{2} \mathrm{P}-Y(\mathbf{l a}-\mathbf{e})$ and/or $\mathrm{Ph}_{2} \mathrm{P}(E)-Y$ (2a-e) are identified as major $\mathrm{P}$-containing products. For the other divalent metal salts of $\mathrm{Zn}, \mathrm{Ge}$ and $\mathrm{Pb}$ studied, the same trends were discovered (Supplementary Figs $1-21$ ). For $E=\mathrm{Se}$ (Supplementary Figs 1-2) in the absence of additional additives, $\mathbf{1 a}$ and $\mathbf{1 b}$ were predominantly found. With amine addition, 1c and $2 \mathrm{c}$ are also formed. With thiol addition, $\mathbf{1 d}$ is formed as a main product, and with alcohol addition, both $\mathbf{1 e}$ and $2 \mathrm{e}$ are formed. For $E=\mathrm{S}$, 1a-e were detected along with $\mathbf{2 b}^{\prime}$ (Supplementary Figs 10-13). For $E=\mathrm{Te}$, none of $\mathrm{Ph}_{2} \mathrm{P}(\mathrm{Te})-Y$ but 1a-e were observed (Supplementary Figs 14-21). Thus, for all the combinations investigated, the reaction of $M X_{2}+E=\mathrm{PPh}_{2} \mathrm{H}+\mathrm{HY}$ appeared to follow equation 1 to produce 1 and/or equation 2 to produce 2 along with the formation of $M_{2} E_{2}$ monomers.

More interestingly, the detection of P-containing compounds for $\mathrm{Cu}$ (I) and In (III) is similar to that for $M$ (II). $\mathrm{C}_{12} \mathrm{H}_{25} \mathrm{SH}$ has been used as a solvent and a ligand to improve the synthesis of $\mathrm{CuInSe}_{2}$ and $\mathrm{CuInS}_{2} \mathrm{QDs}^{22,29-31}$. Representative ${ }^{31} \mathrm{P}$ NMR data for the synthesis of $\mathrm{Cu}_{2} \mathrm{Se}, \mathrm{In}_{2} \mathrm{Se}_{3}$ and $\mathrm{CuInSe} \mathrm{C}_{2}$ using $\mathrm{Se}=\mathrm{PPh}_{2} \mathrm{H}$ and $\mathrm{S}=\mathrm{PPh}_{2} \mathrm{H}$ as the Se and $\mathrm{S}$ precursors are shown in Fig. 4, and for the synthesis of $\mathrm{Cu}_{2} \mathrm{~S}, \mathrm{In}_{2} \mathrm{~S}_{3}$ and $\mathrm{CuInS}_{2}$ in Supplementary 
a

$2 \mathrm{Cd}(\mathrm{OA})_{2}+1 \mathrm{TeTOP}+2 \mathrm{HPPh}_{2}$

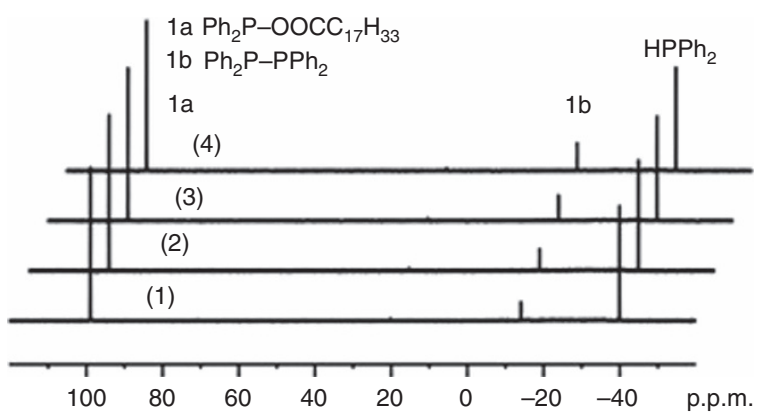

C

$2 \mathrm{Cd}(\mathrm{OA})_{2}+1 \mathrm{TeTOP}+2 \mathrm{HPPh}_{2}+2 \mathrm{C}_{12} \mathrm{H}_{25} \mathrm{SH}$

1d $\mathrm{Ph}_{2} \mathrm{P}-\mathrm{SC}_{12} \mathrm{H}_{25}$

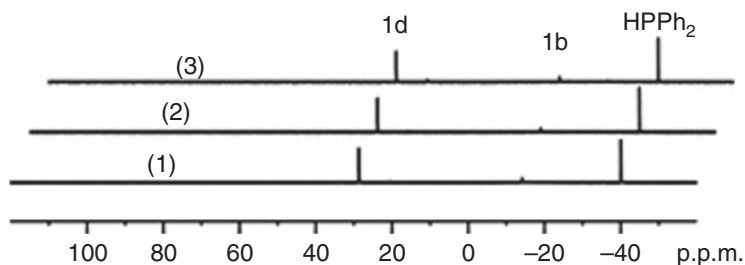

b

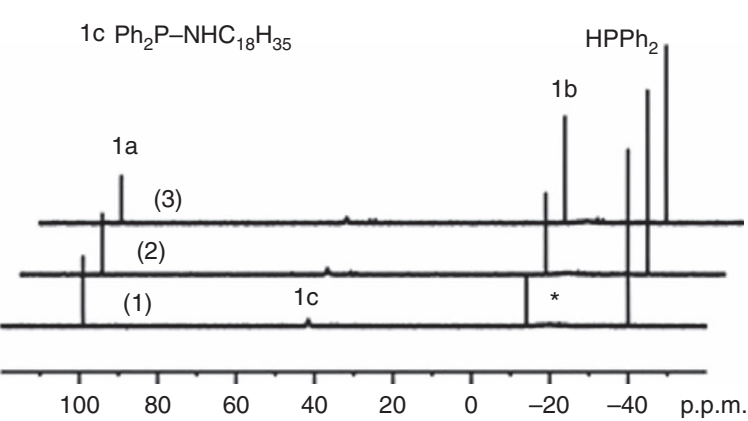

d

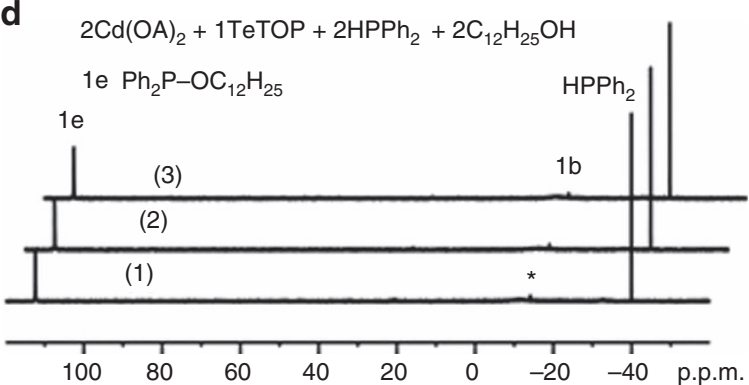

Figure 3 | ${ }^{31} \mathbf{P}$ NMR spectra of CdTe reaction mixtures with Te precursor. (a) $2 \mathrm{Cd}\left(\mathrm{OOCC}_{17} \mathrm{H}_{33}\right)_{2}+\mathrm{TeTOP}+\mathrm{HPPh}_{2}$. (b) $2 \mathrm{Cd}\left(\mathrm{OOCC} \mathrm{C}_{17} \mathrm{H}_{33}\right)_{2}+$ $\mathrm{TeTOP}+\mathrm{HPPh}_{2}+2 \mathrm{C}_{18} \mathrm{H}_{35} \mathrm{NH}_{2}$. (c) $2 \mathrm{Cd}\left(\mathrm{OOCC}_{17} \mathrm{H}_{33}\right)_{2}+\mathrm{TeTOP}+\mathrm{HPPh}_{2}+2 \mathrm{C}_{12} \mathrm{H}_{25} \mathrm{SH}$. (d) $2 \mathrm{Cd}\left(\mathrm{OOCC}_{17} \mathrm{H}_{33}\right)_{2}+\mathrm{TeTOP}+\mathrm{HPPh}+2 \mathrm{C}_{12} \mathrm{H}_{25} \mathrm{OH}$. The experiments were performed at RT for 15 (1), 30 (2), 45 (3) and 60 min (4) for $\mathbf{a}$, and 15 (1), 30 (2) and 60 min (3) for the rest. The peak denoted with an asterisk $\left(^{\star}\right)$ is TOP complexed to $\mathrm{Cd}$ (ref. 23).

Figs 22 and 23. In the presence of $\mathrm{CuI}, \mathrm{C}_{12} \mathrm{H}_{25} \mathrm{SH}$ and $\mathrm{Se}=\mathrm{PPh}_{2} \mathrm{H}$ (Fig. 4a), 2d $\left(\mathrm{Ph}_{2} \mathrm{P}(\mathrm{Se})-\mathrm{SC}_{12} \mathrm{H}_{25}\right)$ is formed as $\mathrm{Se}=\mathrm{PPh}_{2} \mathrm{H}$ is consumed. The absence of $1 \mathrm{~d}$ $\left(\mathrm{Ph}_{2} \mathrm{P}-\mathrm{SC}_{12} \mathrm{H}_{25}\right)$ could be because of the equilibrium of $\mathbf{1 d}+\mathrm{Se}=\mathrm{PPh}_{2} \mathrm{H} \rightleftharpoons \mathbf{2 d}+\mathrm{HPPh}_{2}$ being weighted towards the right (Supplementary Fig. 1, Supplementary Table 2 and Supplementary Note 2). As mentioned before, 1d and 2d should have their own formation path. The addition of amine (Fig. 4b) leads to the product $2 \mathrm{c}\left(\mathrm{Ph}_{2} \mathrm{P}(\mathrm{Se})-\mathrm{NHC}_{18} \mathrm{H}_{35}\right)$, in addition to $1 d$ and salt $\mathrm{Ph}_{2} \mathrm{P}\left(\mathrm{Se}_{2}\right) \mathrm{NH}_{2} \mathrm{C}_{18} \mathrm{H}_{35}$ (which can have resulted from the reaction of $\left.\mathrm{Se}=\mathrm{PPh}_{2} \mathrm{H}+\mathrm{C}_{18} \mathrm{H}_{35} \mathrm{NH}_{2}\right)^{16,24,25}$. The addition of alcohol (Fig. $4 c)$ results in $2 \mathrm{e}\left(\mathrm{Ph}_{2} \mathrm{P}(\mathrm{Se})-\right.$ $\left.\mathrm{OC}_{12} \mathrm{H}_{25}\right)$, in addition to $2 \mathbf{d}$. The absence of $\mathbf{1 e}\left(\mathrm{Ph}_{2} \mathrm{P}-\mathrm{OC}_{12} \mathrm{H}_{25}\right)$ could be because of the equilibrium of $\mathbf{1 e}+\mathrm{Se}=\mathrm{PPh}_{2} \mathrm{H} \rightleftharpoons 2 \mathbf{e}+$ $\mathrm{HPPh}_{2}$ being weighted towards the right (Supplementary Fig. 2, Supplementary Table 2 and Supplementary Note 2).

Indium, as expected, is more reactive under the same reaction conditions where $\mathrm{Se}=\mathrm{PPh}_{2} \mathrm{H}$ completely reacts at $80^{\circ} \mathrm{C}$ per $10 \mathrm{~min}$ (Figs $4 \mathrm{~d}-2$ ) compared with Fig. $4 \mathrm{a}^{22}$. Intriguingly, at RT per $15 \mathrm{~min}$ (Fig. $4 \mathrm{e}$ with expansion), the additional peaks near free $\mathrm{Se}=\mathrm{PPh}_{2} \mathrm{H}$ ( $\sim 7.3$ p.p.m.) are readily interpreted as coordinated $\mathrm{Se}=\mathrm{PPh}_{2} \mathrm{H}$ to In (Fig. $4 \mathrm{e}$ and Supplementary Fig. 22). The products $1 \mathbf{d}$ and $2 \mathbf{d}$ are observed with the absence of $\mathrm{Se}=\mathrm{PPh}_{2} \mathrm{H}$ (Fig. 4d, the In-only experiment), whereas only $\mathbf{2 d}$ is formed in the reaction with the presence of $\mathrm{Se}=\mathrm{PPh}_{2} \mathrm{H}$ (Fig. $4 \mathrm{f}$ with both the presence of $\mathrm{Cu}$ and $\mathrm{In}$ ). Thus, the observation of Compounds $\mathbf{1}$ and $\mathbf{2}$ could be affected by several factors, including the equilibrium of $\mathbf{1}+\mathrm{Se}=\mathrm{PPh}_{2} \mathrm{H} \rightleftharpoons \mathbf{2}+\mathrm{HPPh}_{2}$, which could be weighted towards the right (Supplementary Table 2 and Supplementary Note 2), similar to $\mathrm{TOP}+\mathrm{Se}=\mathrm{PPh}_{2} \mathrm{H} \rightleftharpoons$ $\mathrm{SeTOP}+\mathrm{HPPh}_{2}$ (refs 15,23), except for $\mathbf{1 b}+\mathrm{Se}=\mathrm{PPh}_{2} \mathrm{H} \rightleftharpoons \mathbf{2 b}$ $+\mathrm{HPPh}_{2}$ (refs 21,23-25).

It is critical to perform additional experimental investigation regarding the formation of Compound $\mathbf{2}$ from a direct path. Figure 5 shows the corroborative evidence for equation 2 (Figs 6 and 7 and Supplementary Figs 1-9). These experiments relied on the independent preparation of cadmium bis(diselenophosphinate) $\left(\mathrm{Cd}\left(\mathrm{Se}_{2} \mathrm{PPh}_{2}\right)_{2}, 3\right)^{24}$, which reacted with $\mathrm{Cd}(\mathrm{OA})_{2}$ in the presence of $\mathrm{HY}$ of $\mathrm{C}_{18} \mathrm{H}_{35} \mathrm{NH}_{2}$ (a), $\mathrm{C}_{12} \mathrm{H}_{25} \mathrm{SH} \quad$ (b) and $\mathrm{C}_{12} \mathrm{H}_{25} \mathrm{OH}$ (c). The reaction of $\mathbf{3}+\mathrm{Cd}(\mathrm{OA})_{2}+\mathrm{HY}$ leads to $\mathbf{2 c}, \mathbf{2} \mathbf{d}$ and $\mathbf{2 e}$, respectively. It is noteworthy that $\mathbf{1}$ was not detected. The addition of oleic acid did not lead to 2a (not shown). These results suggest that equation 2 is active at the appropriate temperatures tested (with the amine, thiol and alcohol, but not with the acid). According to the previous study on $3+\mathrm{Cd}(\mathrm{OA})_{2}$ (ref. 24), it is reasonable that the presence of $\mathrm{HPPh}_{2}$ could speed up equation 2 . As shown by Supplementary Fig. 24, the catalytic amount of $\mathrm{HPPh}_{2}$ (0.05 eq. based on 3) accelerated significantly each of the three reactions, with 2 still being the main product. With more $\mathrm{HPPh}_{2}$ (1.00 eq. based on 3), additional 1c (with 1b), 1d (with $\mathbf{1 a}$ and $\mathbf{2 a}$ ) and $\mathbf{1 e}$ were detected, respectively. Thus, $\mathrm{HPPh}_{2}$ could also initiate another equation 1 to $\mathbf{1}+\mathrm{Cd}_{2} \mathrm{Se}_{2}$ (via $\mathbf{A}$ $\left(\mathrm{Cd}\left(\mathrm{SePPh}_{2}\right)_{2}\right)$ as shown in Supplementary Fig. 25). The results shown by Fig. 5 and Supplementary Fig. 24 clearly support that the equilibrium of $\mathbf{1 e}+\mathrm{Se}=\mathrm{PPh}_{2} \mathrm{H} \rightleftharpoons \mathbf{2 e}+\mathrm{HPPh}_{2}$ is weighted towards the right, which is in agreement with our DFT examination shown in Supplementary Table 2 and Supplementary Note 2 .

Figure 6 presents a schematic interpretation of our experimental results (shown in Figs $1-5$ and Supplementary Figs 1-24). When a mixture of metal carboxylate and chalcogenide TOP compound (ETOP) was mixed with dialkylphosphine such as $\mathrm{HPPh}_{2}$ with or without the presence of additives such as amines, thiols and/or alcohols, the formation of NCs begins with chalcogen $E$ exchange, namely $E \mathrm{TOP}+\mathrm{HPPh}_{2} \rightleftharpoons \mathrm{TOP}+E=\mathrm{PPh}_{2} \mathrm{H}$ (refs 15,23-25), the exchange of which activates the chalcogenide. Subsequently, the activated $E=\mathrm{PPh}_{2} \mathrm{H}$ reacts by 
a $1 \mathrm{Cul} / \mathrm{HSC}_{12} \mathrm{H}_{25}+2 \mathrm{Se}=\mathrm{PPh}_{2} \mathrm{H}$

2d $\mathrm{Ph}_{2} \mathrm{P}(\mathrm{Se})-\mathrm{SC}_{12} \mathrm{H}_{25}$

55.5 p.p.m, $J_{\text {P-Se }}=800 \mathrm{~Hz}$

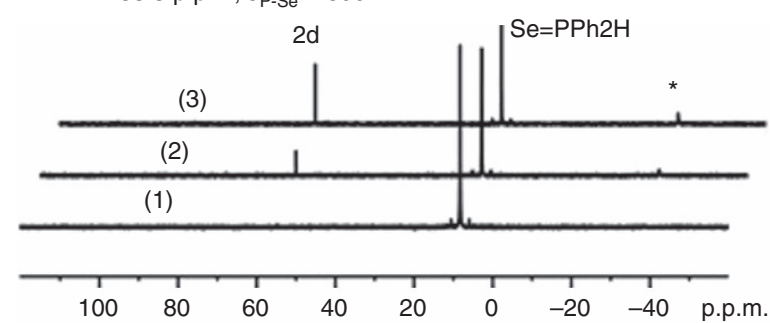

b

$1 \mathrm{Cul} / \mathrm{HSC}_{12} \mathrm{H}_{25}+2 \mathrm{Se}=\mathrm{PPh}_{2} \mathrm{H}+\mathrm{SC}_{18} \mathrm{H}_{35} \mathrm{NH}_{2}$

1d $\mathrm{Ph}_{2} \mathrm{P}-\mathrm{SC}_{12} \mathrm{H}_{35} \quad+22.8$ p.p.m $J_{\mathrm{P}-\mathrm{Se}}=607 \mathrm{~Hz}$

2c $\mathrm{Ph}_{2} \mathrm{P}(\mathrm{Se})-\mathrm{NHC}_{18} \mathrm{H}_{35}$
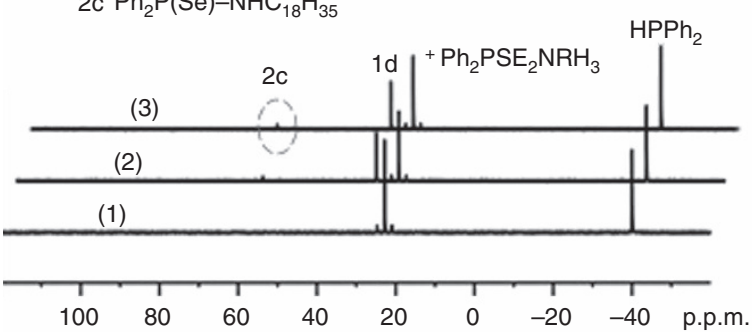

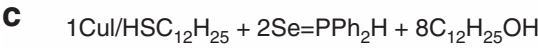

$2 \mathrm{~d} \mathrm{Ph}_{2} \mathrm{P}(\mathrm{Se})-\mathrm{SC}_{12} \mathrm{H}_{25}$

2e $\mathrm{Ph}_{2} \mathrm{P}(\mathrm{Se})-\mathrm{OC}_{12} \mathrm{H}_{25}$

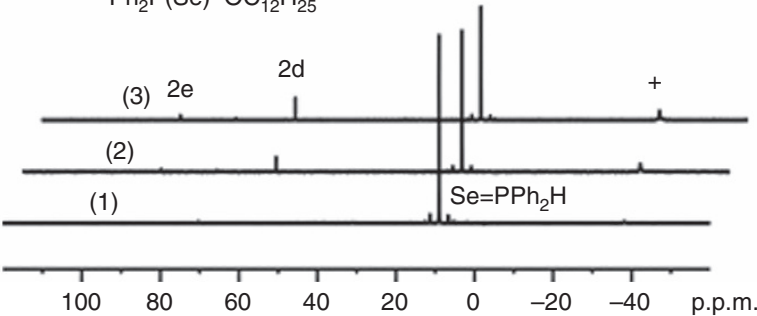

d

$1 \ln (\mathrm{OAc})_{3} / \mathrm{HSC}_{12} \mathrm{H}_{25}+2 \mathrm{Se}=\mathrm{PPh}_{2} \mathrm{H}$

1d $\mathrm{Ph}_{2} \mathrm{P}-\mathrm{SC}_{12} \mathrm{H}_{25}$

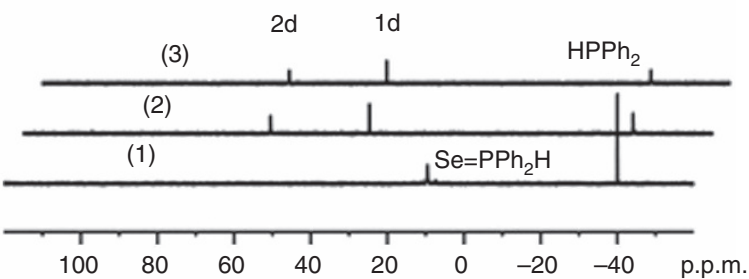

e

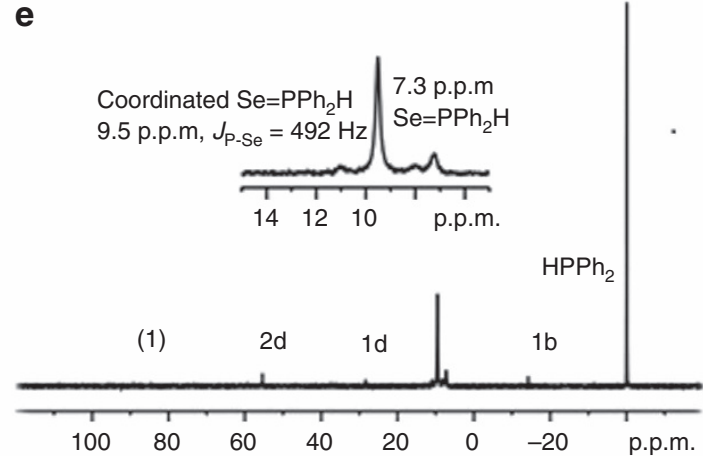

f

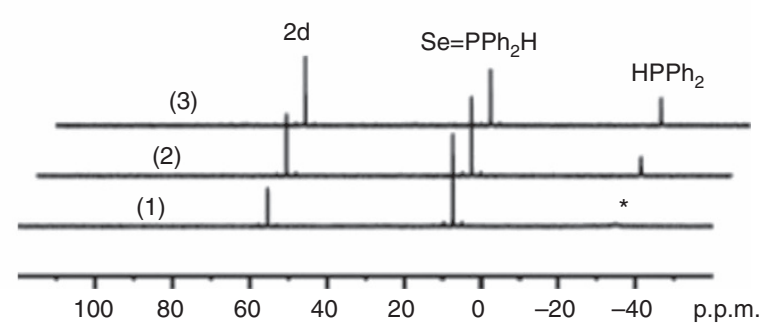

Figure $\left.4\right|^{31} \mathbf{P}$ NMR spectra of $\mathbf{C u} /$ In-containing reaction mixtures. (a) $\mathrm{Cul} / \mathrm{C}_{12} \mathrm{H}_{25} \mathrm{SH}+2 \mathrm{Se}=\mathrm{PPh}_{2} \mathrm{H}$, with $\mathrm{RT}(1), 80^{\circ} \mathrm{C}$ per 10 min $(2)$ and $100{ }^{\circ} \mathrm{C}$ per 10 min (3). (b) Cul $/ \mathrm{C}_{12} \mathrm{H}_{25} \mathrm{SH}+2 \mathrm{Se}=\mathrm{PPh}_{2} \mathrm{H}+8 \mathrm{C}_{18} \mathrm{H}_{35} \mathrm{NH}_{2}$, with RT per $10 \mathrm{~min}$ (1), $100^{\circ} \mathrm{C}$ per $15 \mathrm{~min}$ (2) and $100^{\circ} \mathrm{C}$ per $75 \mathrm{~min}(3)$. (c) Cul/ $\mathrm{C}_{12} \mathrm{H}_{25} \mathrm{SH}+2 \mathrm{Se}=\mathrm{PPh}_{2} \mathrm{H}+8 \mathrm{C}_{12} \mathrm{H}_{25} \mathrm{OH}$, with RT (1), $80^{\circ} \mathrm{C}$ per $10 \mathrm{~min}(2), 100^{\circ} \mathrm{C}$ per $10 \min$ (3). (d,e) In $(\mathrm{OAc})_{3} / \mathrm{C}_{12} \mathrm{H}_{25} \mathrm{SH}+2 \mathrm{Se}=\mathrm{PPh}_{2} \mathrm{H}$, with RT per $15 \mathrm{~min}(1), 80^{\circ} \mathrm{C}$ per $10 \mathrm{~min}(2), 100^{\circ} \mathrm{C}$ per $10 \mathrm{~min}$ (3) for $\mathbf{d}$ and $\mathrm{RT}$ per $15 \mathrm{~min}$ (1) for e (repeated with $\left.512 \mathrm{scans}\right) .(\mathbf{f}) \mathrm{Cul} / \mathrm{C}_{12} \mathrm{H} \mathrm{H}_{25} \mathrm{SH}+\mathrm{In}(\mathrm{OAC})_{3} /$ $\mathrm{C}_{12} \mathrm{H}_{25} \mathrm{SH}+4 \mathrm{Se}=\mathrm{PPh}_{2} \mathrm{H}$, with RT per $15 \mathrm{~min}(1), 80^{\circ} \mathrm{C}$ per $5 \mathrm{~min}(2)$ and $100^{\circ} \mathrm{C}$ per $5 \mathrm{~min}$ (3). The peak denoted with an asterisk $\left({ }^{\star}\right)$ was assigned to $\mathrm{HPPh}_{2}$ complexed to $\mathrm{Cu}$ (ref. 22).

coordinating the chalcogenide atom to the metal centre (equation 3). In the absence of $\mathrm{HPPh}_{2}$, the dioctylphosphine impurity in TOP could play the same chemical function, which was only realized recently ${ }^{15,17-23}$.

$$
\begin{gathered}
M X_{n}+n E=\mathrm{PPh}_{2} \mathbf{H}^{\prime} \rightarrow X_{n} M\left(E=\mathrm{PPh}_{2} \mathbf{H}^{\prime}\right)_{n} \\
X_{n} M\left(E=\mathrm{PPh}_{2} \mathbf{H}^{\prime}\right)_{n} \rightarrow M-\left(E \mathrm{PPh}_{2}\right)_{n}(\mathbf{A})+n \mathbf{H}^{\prime}-X \\
{\left[M-(E \mathrm{PPh})_{n}\right]_{2}(\mathbf{D})+n \mathbf{H}^{\prime \prime} Y \rightarrow n E=\mathrm{PPh}_{2} \mathbf{H}^{\prime \prime}+M_{2} E_{n}+n \mathrm{Ph}_{2} \mathrm{P}-Y}
\end{gathered}
$$

$$
\left[M-\left(E \mathrm{PPh}_{2}\right)_{n}\right]_{2}(\mathbf{D})+n \mathbf{H}^{\prime \prime} Y \rightarrow n \mathbf{H}^{\prime \prime} \mathrm{PPh}_{2}+M_{2} E_{n}+n \mathrm{Ph}_{2} \mathrm{P}(E)-Y
$$

Following the coordination (equation 3), as experimentally demonstrated by Fig. 4e, intermediate $\mathbf{A}\left(M-\left(E P h_{2}\right)_{n}\right)$ is formed, accompanied by $\mathrm{H}-X$ (equation 4). It seems reasonable that the $\mathrm{H}-\mathrm{P}$ bond of $E=\mathrm{PPh}_{2} \mathrm{H}$ is strong enough to sustain the coordination to the metal, but weak enough for $\mathrm{H}$ to leave and to form $\mathrm{HX}$. The chalcogen coordination to the metal not only increases the acidity of the P-bound $\mathrm{H}$ but also makes $\mathrm{H}$ accessible to the adjacent $X$ group. Thus, in the forward reaction direction, the $\mathrm{P}$-bound $\mathrm{H}$ leads to the elimination of the ligand $X$ resulting in $\mathbf{A}$ and $H X$ (equation 4). In the next step, we propose $\mathbf{A}$ reacts with $\mathrm{HY}$ first to give $\mathbf{B}$ and/or $\mathbf{C}$, which then dimerize towards $\mathbf{E}$ and/or $\mathbf{F}$, respectively. At the same time, A could first dimerize towards $\mathbf{D},\left[M-\left(E \mathrm{PPh}_{2}\right)_{n}\right]_{2}$, and then reacts with $\mathbf{H Y}$ to give $\mathbf{E}$ and/or $\mathbf{F}$. For example, dimer $\mathbf{D}$ reacts with $\mathrm{HY}$ to produce $E=\mathrm{PPh}_{2} \mathrm{H}+M_{2} E_{n}+\mathrm{Ph}_{2} \mathrm{P}-Y(\mathbf{1}$; equation 5) or $\mathrm{HPPh}_{2}+M_{2} E_{n}+\mathrm{Ph}_{2} \mathrm{P}(E)-Y$ (2; equation 6). Our proposed pathway leading to the observation of $\mathbf{1}$ and $\mathbf{2}$ significantly differs from the pathway proposed in 2010 (ref. 15), as detailed in Supplementary Fig. 26 and Supplementary Note 3. One major difference is intermediate $\mathbf{A}$ and its formation and subsequent evolution (equations 3-6), which were not 

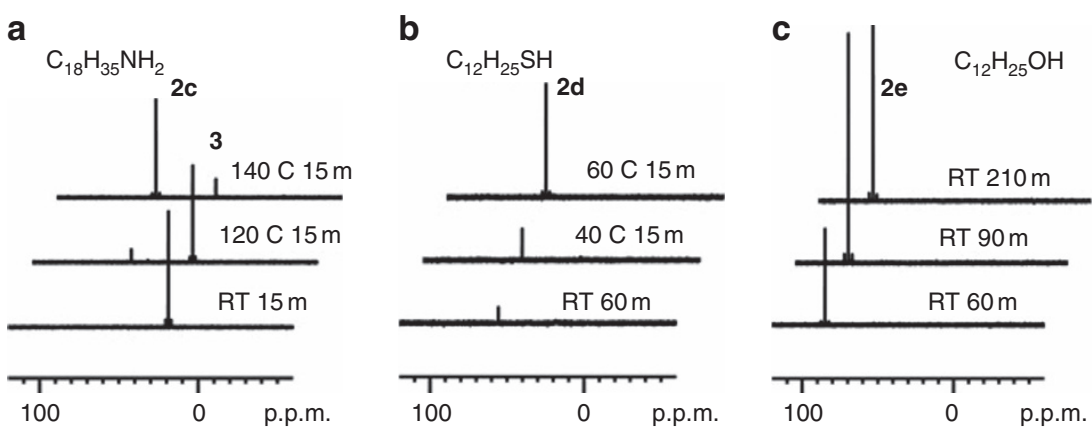

Figure $\mathbf{5}$ | ${ }^{31} \mathbf{P}$ NMR spectra of reaction mixtures of $\mathbf{3}+\mathbf{6} \mathbf{C d}(\mathbf{O A})_{\mathbf{2}}+\mathbf{H Y}$. (a) $16 \mathrm{RNH}_{2}$. (b) $4 \mathrm{RSH}$. (c) $16 \mathrm{ROH}$. The slowest disappearance of $\mathbf{3}$ occurs with the use of amine, the trend of which is in agreement with that shown in Fig. 1. The relevant pathway to the formation of monomers and $\mathbf{2}$ is shown in Supplementary Fig. 25.

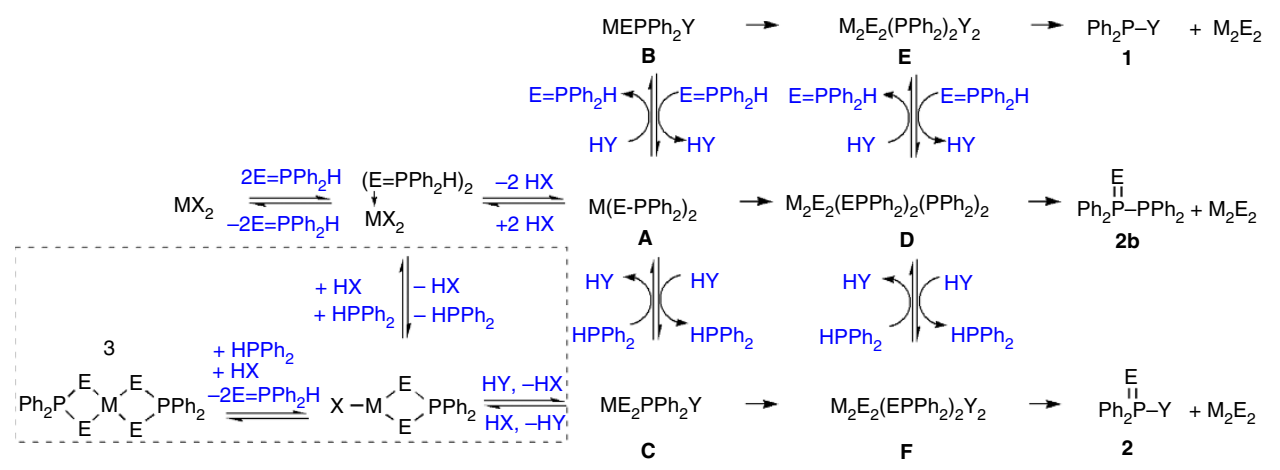

Figure 6 | Schematic of the general pathway for formation of $\mathbf{M}_{\mathbf{2}} \mathbf{E}_{\mathbf{n}}$ monomers. For simplicity, this figure is drawn for $M$ (II) only at low temperature from metal carboxylate $\left(M X_{2}\right)$ and dialkylphosphine chalcogenide $\left(E=\mathrm{PPh}_{2} \mathrm{H}\right)$ with the use of additive $\mathrm{HY}$. Specific schemes for the other metal valences can be constructed accordingly. $E=\mathrm{S}$, Se or Te. When $\mathrm{HY}=R \mathrm{COOH}(\mathbf{a}), \mathrm{HPPh}_{2}(\mathbf{b}), R \mathrm{NH}_{2}(\mathbf{c}), R S \mathrm{H}$ (d) and $R \mathrm{OH}(\mathbf{e}), \mathrm{Compounds} \mathbf{1}$ and $\mathbf{2}$ are labelled as $\mathbf{1 a}-\mathbf{e}$ and $\mathbf{2 a}-\mathbf{e}$, respectively. The equilibrium of $\mathbf{1}+E=\mathrm{PPh}_{2} \mathrm{H} \rightleftharpoons \mathbf{2}+\mathrm{HPPh}_{2}$ is worthy of notice (Supplementary Table 2 and Supplementary Note 2). Note that another secondary phosphine, dicyclohexylphosphine $\left(\mathrm{HPCy}_{2}\right.$ ), was also tested (as shown in Supplementary Figs 1 and 3); precursor $E=P C y_{2} \mathrm{H}$ instead of $E=P P h_{2} \mathrm{H}$ also leads to Compound $\mathrm{Cy}_{2} \mathrm{P}-Y(\mathbf{1})$ and $\mathrm{Cy}_{2} \mathrm{P}(E)-Y(\mathbf{2})$. The correlation between the reactivity of $E=P R_{2} \mathrm{H}$ (with $R=\mathrm{Ph}$ or $C y$ ) and the size of resulting $\mathrm{NCs}$ is the subject of another study. The dotted box is for a system to start from single-source precursors (such as $\mathbf{3}$ shown in Supplementary Fig. 25 with $E=$ Se and $M=C d(I I)$ ). See Supplementary Fig. 26 and Supplementary Note 3 for the difference of the putative mechanisms proposed by ref. 15 and by the present study. With $Y=\mathrm{PPh}_{2}$, intermediate $\mathbf{D}$ in nature is $\mathbf{F}$. Here two competing pathways are proposed for the formation of $M_{2} E_{n}$ monomer: one is $\mathbf{A}-(\mathbf{B}$ or $\mathbf{D})-\mathbf{E}-\mathbf{1}+M_{2} E_{n}$, the other is $\mathbf{A}-(\mathbf{C}$ or $\mathbf{D})-\mathbf{F}-\mathbf{2}+M_{2} E_{n}$.

addressed in the work of 2010 but are clearly elucidated in the present study. Note that the pathway proposed in 2010 does not address at all the detection of $\mathbf{1 b}\left(\mathrm{PPh}_{2}-\mathrm{PPh}_{2}, 14\right.$ p.p.m. $)$ from the reactions of $\mathrm{Pb}(\mathrm{OA})_{2}+\mathrm{Se}=\mathrm{PPh}_{2} \mathrm{H}$ and $\mathrm{Cd}(\mathrm{OA})_{2}+\mathrm{Se}=\mathrm{PPh}_{2} \mathrm{H}$ at RT.

Figure 6 is formulated for the case of $M$ (II), but also applies to $M$ (I) and $M$ (III) where their monomers are accordingly proposed to be $M_{2} E$ and $M_{2} E_{3}$, respectively. Obviously, $\mathbf{A}$ and $\mathbf{B}$ are connected by equilibrium $\mathbf{A}+\mathrm{HY} \rightleftharpoons \mathbf{B}+E=\mathrm{PPh}_{2} \mathrm{H}$, while $\mathbf{A}$ and $\mathbf{C}$ by $\mathbf{A}+\mathrm{HY} \rightleftharpoons \mathbf{C}+\mathrm{HPPh}_{2}$. Consequently, $\mathbf{B}$ and $\mathbf{C}$ are correlated by $\mathbf{B}+E=\mathrm{PPh}_{2} \mathrm{H} \rightleftharpoons \mathbf{C}+\mathrm{HPPh}_{2}$, similarly to Compounds $\mathbf{1}$ and $\mathbf{2}$ by $\mathbf{1}+E=\mathrm{PPh}_{2} \mathrm{H} \rightleftharpoons \mathbf{2}+\mathrm{HPPh}_{2}$. These equilibria are clearly affected by the relative amount of $\mathrm{HPPh}_{2}, E=\mathrm{PPh}_{2} \mathrm{H}$ and $\mathrm{HY}$. The formation of the monomer $M_{2} E_{2}$ occurs via the ligand loss of $\mathbf{1}$ from intermediate $\mathbf{E}$ (equation 1) and/or 2 from intermediate $\mathbf{F}$ (equation 2). With $Y=\mathrm{PPh}_{2}$, intermediate $\mathbf{D}$ in nature is $\mathbf{F}$; thus, $\mathbf{D}$ can result in $\mathbf{2} \mathbf{b}+M_{2} E_{n}$ (equation 2).

DFT study. To further understand the fundamental chemistry involved in the putative pathway proposed in Fig. 6, let us turn our attention to the possible isomers with their bonding skeletons of each of the intermediate species $\mathbf{A}$ to $\mathbf{F}$ proposed in Fig. 6 . In addition to metal ions $(M)$, chalcogenides $(E)$ and diphenylphosphinio species $\left(\mathrm{Ph}_{2} \mathrm{P}\right)$, intermediates $\mathbf{B}$ to $\mathbf{F}$ contain the various $Y$ groups. Consequently, each intermediate has multiple possible constitutional isomers, while most possible combinations of bonds, such as $\mathrm{P}-E, E-E, \mathrm{P}-\mathrm{P}, \mathrm{P}-Y$ and $E-Y$ bonds, exist in well-known compounds, and all such bonds can in principle coordinate to metal ions leading to multiple possibilities. For example, for $Y=$ NHR in Fig. 6, the N could bond to Cd, P or Se; if $\mathrm{N}$ is bound to $\mathrm{P}$, two bonding arrangements $(M-\mathrm{P}-\mathrm{N}$ and $M-\mathrm{N}-\mathrm{P}$ ) could in principle be expected. These uncertainties are amenable to DFT calculations, which provide useful information to minimize positional isomers, with the cancellation of errors in the DFT approximation ${ }^{39-42}$. In this way, the calculated bonding trends should be reliable. The possibilities in Fig. 7 are distinguished by DFT calculations at the M06//B3LYP/ 6-31++G (d, p), Stuttgart/Dresden (SDD) level in ODE media. Our DFT-calculated structures and energies of many more possible isomers are shown in Supplementary Tables 3-25 including structural, geometric and rotational isomers. An additional description and discussion of the isomers of each intermediate $\mathbf{A}$ to $\mathbf{F}$ can be found immediately before Supplementary Tables 3-17. 


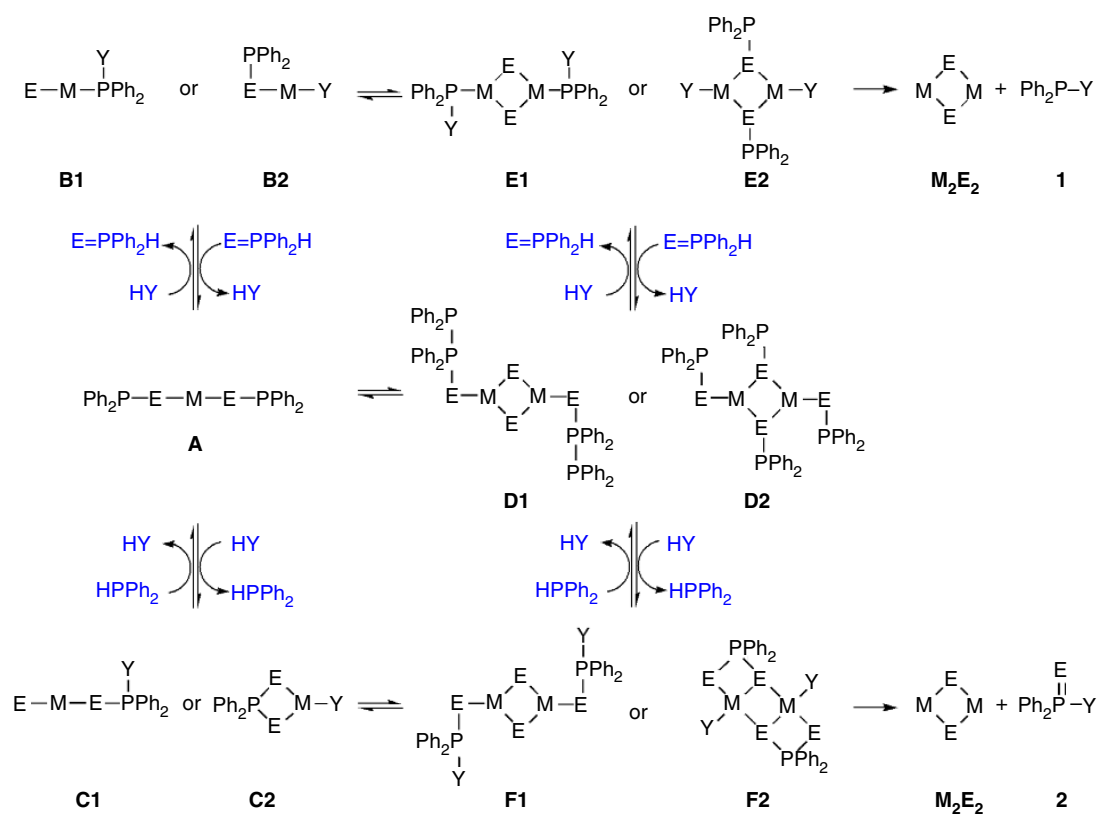

Figure 7 | Possible isomers with binding skeletons. Here two of the most probable constitutional isomers of intermediates $\mathbf{B}$ to $\mathbf{F}$ are shown; there are 99 CdSe-containing isomer structures computed as shown Supplementary Tables 4-17. With $M=\mathrm{Cd}$ and $E=\mathrm{Se}, \mathbf{B} 1$ and $\mathbf{C 1}$ are favoured for $Y=\mathrm{NHR}$, whereas $\mathbf{B 2}$ and $\mathbf{C 2}$ are preferred for $Y=\mathrm{SR}$, OOCR. For $Y=\mathrm{OR}$, the distinction is not clear cut. For the immediate precursors $\mathbf{E}$ and $\mathbf{F}$ leading to monomers $\mathrm{Cd} \mathrm{S}_{2} \mathrm{Se}_{2}$ with Compounds $\mathbf{1}$ and $\mathbf{2}$, respectively, E1 and $\mathbf{F 1}$ are favoured for $Y=\mathrm{NHR}$ and OR, whereas E2 and $\mathbf{F 2}$ are preferred for $Y=\mathrm{SR}$ and OOCR. For $Y=\mathrm{PPh}$, D2 is more stable than D1. Possibly, the release of Compound $\mathbf{1}$ is more apparent from E1 (via the M-P bond cleavage) than from E2, while Compound $\mathbf{2}$ from $\mathbf{F 1}$ (via the $M-E$ bond cleavage) than from $\mathbf{F 2}$.

The most stable $\mathbf{A}$ is with the $\mathrm{P}-\mathrm{Se}-\mathrm{Cd}-\mathrm{Se}-\mathrm{P}$ skeleton among the seven isomers computed (Supplementary Table 3). For the two predominant species $\mathbf{B} 1$ and $\mathbf{B 2}$ found, they have the Se-Cd$\mathbf{P}-\boldsymbol{Y}$ and $\mathrm{P}-\mathrm{Se}-\mathrm{Cd}-\boldsymbol{Y}$ skeletons, respectively. B1 versus B2 includes $\mathrm{P}-Y$ versus $M-Y$ bonds, without $E-Y$ bonds. With $Y=\mathrm{NHR}$ for CdSe (Supplementary Table 4), the B1 isomer was calculated to be $10.1 \mathrm{~kJ} \mathrm{~mol}^{-1}$ (free energy $\Delta G$ ) more stable than B2. This energy trend of $\mathbf{B 1}<\mathbf{B 2}$ was not found for the other $Y$. For $Y=S R$ (Supplementary Table 4), the distinction is quite clear that the direct metal-bound $\mathbf{B 2}$ isomer $\mathrm{P}-\mathrm{Se}-\mathbf{C d}-\mathbf{S R}$ was calculated to be $82.5 \mathrm{~kJ} \mathrm{~mol}^{-1}$ more stable than the B1 isomer with Se-Cd-P-SR. For $Y=O R$ (Supplementary Table 5), the B2 isomer with the $\mathrm{P}-\mathrm{Se}-\mathrm{Cd}-\mathrm{OR}$ skeleton was found to be at the lowest energy, but the $\mathbf{B} \mathbf{1}$ isomer with the $\mathrm{Se}-\mathrm{Cd}-\mathbf{P}-\mathbf{O R}$ skeleton was only $6.9 \mathrm{~kJ} \mathrm{~mol}^{-1}$ higher-an energy difference that is close to the accuracy of the DFT method and could be affected by the exact nature of various $R$ groups, the solvent used and the temperature employed. For $Y=$ OOCR (Supplementary Table 6), the directly metal-bound $\mathbf{B} 2$ isomer is $111.3 \mathrm{~kJ} \mathrm{~mol}^{-1}$ more stable than the B1 isomer with Se-Cd-P-OOCR. For $Y=\mathrm{PPh}_{2}$ (Supplementary Table 6), B2 is $58.7 \mathrm{~kJ} \mathrm{~mol}^{-1}$ more stable than B1.

Intermediate $\mathbf{C}$ with an extra chalcogen $E$ atom compared with intermediate $\mathbf{B}$ evidently has more constitutional possibilities. Intriguingly, the connectivity follows similar patterns to that of intermediate B. For $Y=\mathrm{NHR}$ (Supplementary Table 7), C1 with the $\mathrm{Se}-\mathrm{Cd}-\mathrm{Se}-\mathbf{P}-\mathrm{N}$ connectivity has the lowest energy. Note that there is an extra Se inserted between the $\mathrm{Cd}$ and $\mathrm{P}$ atoms. The most stable $\mathrm{Cd}-\mathrm{N}$-bound species $\mathbf{C} 2$ was found to contain the four-membered $\mathrm{N}-\mathrm{Cd}^{*}-\mathrm{Se}-\mathrm{P}-\mathrm{Se}-\left(\mathrm{Cd}^{*}\right)$ ring, which was $18.7 \mathrm{~kJ} \mathrm{~mol}^{-1}$ calculated. For $Y=S R$ (Supplementary Table 8), C2 with a direct Cd-SR bond is favoured much more than the other isomers considered. Complexes with this C2-type connectivity but with $Y=\mathrm{SSPPh}_{2}$ have been characterized experimentally ${ }^{35}$. For $Y=O R$ (Supplementary Table 9), C1 and
C2 differ by only $2.3 \mathrm{~kJ} \mathrm{~mol}^{-1}$ and can therefore be considered iso-energetic. For $Y=$ OOCR (Supplementary Table 10), C2 with the direct $\mathrm{Cd}-\mathrm{OOCR}$ bonding is much more stable, similar to the case of $Y=S R$.

Consequently, for $Y=\mathrm{NHR}, \mathbf{B} \mathbf{1}$ and $\mathbf{C} \mathbf{1}$ are preferred. For $Y=\mathrm{O} R$, the selectivity is not obvious. For $Y=\mathrm{S} R$ and OOCR, B2 and $\mathbf{C} 2$ are favoured. Thus, the preference on the bonding skeleton calculated for intermediates $\mathbf{B}$ and $\mathbf{C}$ is similar. The nature of the chalcogenide also affects the relative stability of B1 versus B2 (Supplementary Table 18) as well as that of C1 versus C2 (Supplementary Table 19). For $Y=$ NHR specifically, $\mathbf{B} 2$ and $\mathbf{C} 2$ are stabilized for $E=S$, whereas $\mathbf{B} \mathbf{1}$ and $\mathbf{C} \mathbf{1}$ are more stable for $E=\mathrm{Te}$ than for $E=$ Se. For CdSe, our preliminary efforts on the kinetics associated with the putative pathway $\mathbf{A}+\mathrm{H}-\mathrm{Y} \rightarrow \mathbf{B}+\mathrm{Se}=\mathrm{PPh}_{2} \mathrm{H}$ are presented in Supplementary Figs 28-31 and Supplementary Note 5 with A1b for A and B2a for $\mathbf{B}$. The trend of the kinetics computed seems to be in agreement with our experimental data showing the slowest disappearance of SeTOP (Fig. 1) and of 3 (Fig. 5) is from the batch with $\mathrm{H} Y=\mathrm{RNH}_{2}$.

Intermediates $\mathbf{E}$ and $\mathbf{F}$ are proposed as the very immediate precursors leading to monomers $M_{2} E_{n}$ with Compounds $\mathbf{1}$ and $\mathbf{2}$, respectively. E1 could have resulted from dimerization of $\mathbf{B} 1$ and E2 from B2. F1 could have resulted from dimerization of $\mathbf{C} 1$ and F2 from C2. Again, DFT calculations were performed to address the question of whether the various $Y$ species are bound to $\mathrm{Cd}$ or to Se or to P. Clearly, $\mathbf{E}$ and $\mathbf{F}$ are computationally demanding. Generally, $\mathbf{E}$ isomers follow the trend of $\mathbf{B}$ isomers, and $\mathbf{F}$ follows C: low-energy $\mathbf{B}$ isomers lead to low-energy $\mathbf{E}$, and $\mathbf{C}$ to $\mathbf{F}$. In all cases, the four-membered ring $\mathrm{Cd}^{\star}-\mathrm{Se}-\mathrm{Cd}-\mathrm{Se}-\left(\mathrm{Cd}^{\star}\right)$ was found by minimization. For $Y=\mathrm{NHR}$ (Supplementary Table 11), E1 with the $\mathrm{P}-\mathrm{N}$ bond is much more stable than $\mathbf{E} 2$ with the $\mathrm{Cd}-\mathrm{N}$ bond by $\sim 150 \mathrm{~kJ} \mathrm{~mol}^{-1}$. For $Y=S R$ (Supplementary Table 11), E2 with the Cd-S bond is more stable than E1, but the difference is smaller $\left(32.7 \mathrm{~kJ} \mathrm{~mol}^{-1}\right)$ than that $\left(82.5 \mathrm{~kJ} \mathrm{~mol}^{-1}\right)$ of $\mathbf{B 2}$ versus 
B1. For $Y=\mathrm{OR}$ (Supplementary Table 12), E1 is much more stable than E2, whereas B1 is similar to B2. For $Y=O O C R$ (Supplementary Table 13), isomers such as E2 (with the Cd-Y bond) are the most stable ones found.

Intermediate $\mathbf{F}$ consists of two more $E$ atoms than $\mathbf{E}$. For $Y=$ NHR (Supplementary Table 14), F1, with Se inserted between the $\mathrm{Cd}$ and $\mathrm{P}$, namely $\mathrm{Cd}-\mathrm{Se}-\mathrm{P}-\mathrm{N}$, is $196.6 \mathrm{~kJ} \mathrm{~mol}^{-1}$ more stable than $\mathbf{F} 2$ with the direct $\mathrm{Cd}-\mathrm{N}$ bond. For $Y=\mathrm{S} R$ (Supplementary Table 15), $\mathbf{F} 2$ is $78.0 \mathrm{~kJ} \mathrm{~mol}^{-1}$ more stable than F1. For $Y=\mathrm{OR}$ (Supplementary Table 15), F1 is $126.1 \mathrm{~kJ} \mathrm{~mol}^{-1}$ more stable than F2. For $Y=$ OOCR (Supplementary Table 16), $\mathbf{F} 2$ is $78.8 \mathrm{~kJ} \mathrm{~mol}^{-1}$ more stable than F1. For $Y=\mathrm{PPh}_{2}, \mathbf{D 2}$ (a dimer of A) is more stable than D1 (equivalent to F1) by $86.6 \mathrm{~kJ} \mathrm{~mol}^{-1}$.

Although speculative, our current proposal is that $\mathbf{E}$ and $\mathbf{F}$ (or possibly higher oligomers such as from the dimerization of $\mathbf{E}$ and $\mathbf{F})^{43}$ facilitate the release of $\mathbf{1}$ and 2 , respectively. The release of Compound $\mathbf{1}$ is more apparent from E1 (via the $M-\mathrm{P}$ bond cleavage) than from E2; the Cd-P bond expected to break for E1 to lose 1 has a length of $2.66 \AA$ (longer than $2.58 \AA$ in B1). In addition, the release of Compound $\mathbf{2}$ is more apparent from F1 (via the $M-E$ bond cleavage) than from F2; the Cd-Se bond expected to break for F1 to lose $\mathbf{2}$ has a length of $2.74 \AA$ (longer than $2.69 \AA$ in $\mathbf{C 1}$ ). For the release of $\mathbf{1}$ and $\mathbf{2}$ from E2 and F2, respectively, it seems reasonable that the formation of a $Y-\mathrm{P}$ bond (via the interaction of $Y$ with $\mathrm{Ph}_{2} \mathrm{P}$ and with $\mathrm{Ph}_{2} \mathrm{P}(E)$ ) could be accompanied by the cleavage of $M-Y$ and $\mathrm{P}-E$ bonds ${ }^{44}$. It has been suggested that the oligomerization to $\left[\mathrm{Cd}_{2} \mathrm{Se}_{2}\right]_{m}$ is accompanied by a decrease in free energy for at least $m=6$ (ref. 24); this thermodynamic stability of $\left[M_{2} E_{n}\right]_{m}$ may be the driving force of the overall reaction ${ }^{45}$.

\section{Discussion}

The molecular pathway of precursor evolution to monomers responsible for nucleation at low reaction temperature to semiconductor NCs has been recognized as a major challenge in advancing the design and synthesis of high-quality NCs with high synthetic reproducibility and particle yield. We have successfully rationalized a general reaction pathway for precursor evolution to monomers at low reaction temperatures from the mixture of $M X_{n}+E \mathrm{TOP}+\mathrm{HPPh}_{2}+\mathrm{HY}$ or $M X_{n}+E=\mathrm{PPh}_{2} \mathrm{H}+$ $H Y$. On the basis of the experimental and computational investigations, we propose the monomer of $M_{2} E_{n}$ and its formation accompanied by the loss of ligand $\mathrm{Ph}_{2} \mathrm{P}-Y$ (1) and $\mathrm{Ph}_{2} \mathrm{P}(E)-Y$ (2) via two competing paths. Experimentally, the combination of six metal ions of monovalent, divalent or trivalent, three chalcogenides and five types of additive HY (of carboxylic acid, dialkylphosphine, amine, thiol or alcohol) results in the $\mathrm{P}$-containing products of $\mathrm{Ph}_{2} \mathrm{P}-Y(\mathbf{1})$ and $\mathrm{Ph}_{2} \mathrm{P}(E)-Y(\mathbf{2})$. The in-depth interpretation of the mechanism is supported by our DFT calculations. Our proposed pathway features a series of $\mathrm{H}$-mediated ligand loss/exchange reactions triggered by dialkylphospine chalcogenides (such as $E=\mathrm{PPh}_{2} \mathrm{H}$ ) to form intermediate $\mathbf{A}\left(M-\left(E P \mathrm{Ph}_{2}\right)_{n}\right)$, which leads to intermediate E $\left(Y \mathrm{Ph}_{2} \mathrm{P}-M E_{n} M-\mathrm{PPh}_{2} Y\right.$, equation 1) and intermediate $\mathbf{F}\left(Y \mathrm{Ph}_{2} \mathrm{PE}-M E_{n} \mathrm{M}-E \mathrm{PPh}_{2} Y\right.$, equation 2), the formation of which consists of dimerization and reaction with $\mathrm{HY}$. The disassociation of ligand $\mathbf{1}$ from $\mathbf{E}$ and ligand $\mathbf{2}$ from $\mathbf{F}$ results in $M_{2} E_{n}$ monomers. Clearly, HY participates in the formation of monomers and thus could accelerate nucleation; meanwhile, a large amount of $\mathrm{HY}$ plays the role of a solvent and, thus, could retard nucleation. Importantly, the general pathway applies to metal chalcogenide NCs made from both toxic metals such as $\mathrm{Cd}$ (II) and $\mathrm{Pb}$ (II) and more benign metals such as $\mathrm{Cu}$ (I), $\mathrm{Zn}$ (II) and In (III). The insights into the chemical nature of the $M_{2} E_{n}$ monomer the building block, could provide the basis for the field to enable the manipulation of the chemical processes for rational design and synthesis of a variety of NCs with complex stoichiometry. The use of secondary phosphines together with beneficial additive $\mathrm{HY}$ should be a general and practical avenue to engineer metal chalcogenide NCs at low reaction temperatures with high quality, enhanced synthetic reproducibility and particle yield. We anticipate that the insight gained on the molecular pathway for precursor evolution into various types of $M_{2} E_{n}$ monomers may enable the field to synthesize sophisticated NCs, including phase-change materials, with better-controlled chemical processes via cation exchange as well as doping and co-doping with monovalent and trivalent metal ions ${ }^{46-52}$. We are actively exploring the correlation between the pathway of monomer formation with the formation of magic-size and regular QDs, aiming at the control of product properties including the size and size distribution. In addition, we believe that, similar to the endeavour of the development of organic syntheses, the basic chemistry reported embraces the advance of the NC synthesis from an empirical art to science with pathway-enabled design leading towards the full realization of the NC potential ${ }^{53-57}$.

\section{Methods}

31P NMR measurements. ${ }^{31} \mathrm{P}$ NMR was performed on a Bruker AV-III 400 spectrometer operating at $161.98 \mathrm{MHz}$, referenced with an external standard, $85 \%$

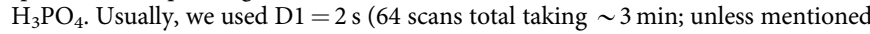
otherwise). NMR samples were usually prepared and loaded in NMR tubes in a glovebox and properly sealed. All chemicals used are commercially available from Sigma-Aldrich and were used as received (or otherwise specified). The used ligands and additives are oleic acid (OA, tech. $90 \%)$, diphenylphosphine $\left(\mathrm{HPPh}_{2}, 99 \%\right.$, Strem Chemicals), oleic amine (OLA, $\mathrm{C}_{18} \mathrm{H}_{35} \mathrm{NH}_{2}$, tech. 70\%), 1-dodecanethiol $\left(\mathrm{C}_{12} \mathrm{H}_{25} \mathrm{SH}, 98 \%\right)$ and lauryl alcohol $\left(\mathrm{C}_{12} \mathrm{H}_{25} \mathrm{OH}, 98 \%\right)$. The elemental chalcogens used are sulfur (S, precipitated, Anachemia), selenium (Se, 200 mesh, 99.999\%, Alfa Aeser) and tellurium (Te, 200 mesh, 99.8\%). For the assignment of Compounds 1 and 2, sodium hydride $\left(\mathrm{NaH}, 95 \%\right.$, dry), chlorodiphenylphosphine $\left(\mathrm{Ph}_{2} \mathrm{P}-\mathrm{Cl}\right.$, 97\%, Alfa Aeser) were used. Compounds $1\left(\mathrm{Ph}_{2} \mathrm{P}-Y\right)$ and $\mathbf{2}\left(\mathrm{Ph}_{2} \mathrm{P}(E)-Y\right)$ detected with NMR are related to the formation of monomers/solutes/NCs, and have been use to explore the formation of monomers since 2006 (refs 13,15,23-25). The $\mathrm{P}$-containing products detected with ${ }^{31} \mathrm{P}$ NMR are listed as follows: 1a $\left(\mathrm{Ph}_{2} \mathrm{P}-\mathrm{OOCC}_{17} \mathrm{H}_{33}\right), \mathbf{l b}\left(\mathrm{Ph}_{2} \mathrm{P}-\mathrm{PPh}_{2}\right), \mathbf{1 c}\left(\mathrm{Ph}_{2} \mathrm{P}-\mathrm{NHC}_{18} \mathrm{H}_{35}\right), \mathbf{1 d}\left(\mathrm{Ph}_{2} \mathrm{P}-\mathrm{SC}_{12} \mathrm{H}_{25}\right)$, 1e $\left(\mathrm{Ph}_{2} \mathrm{P}-\mathrm{OC}_{12} \mathrm{H}_{25}\right), \mathbf{2 a}\left(\mathrm{Ph}_{2} \mathrm{P}(\mathrm{Se})-\mathrm{OOCC}_{17} \mathrm{H}_{33}\right), \mathbf{2 b}\left(\mathrm{Ph}_{2} \mathrm{P}(\mathrm{Se})-\mathrm{PPh}_{2}\right), \mathbf{2} \mathbf{b}$ $\left.\left(\mathrm{Ph}_{2} \mathrm{P}(\mathrm{S})-\mathrm{PPh}_{2}\right), 2 \mathrm{c}\left(\mathrm{Ph}_{2} \mathrm{P}(\mathrm{Se})-\mathrm{NHC}_{18} \mathrm{H}_{35}\right), 2 \mathrm{~d} \mathrm{Ph}_{2} \mathrm{P}(\mathrm{Se})-\mathrm{SC}_{12} \mathrm{H}_{25}\right)$ and $2 \mathrm{e}$ $\left.\mathrm{Ph}_{2} \mathrm{P}(\mathrm{Se})-\mathrm{OC}_{12} \mathrm{H}_{25}\right)$.

Computational. Our DFT calculations were performed using Gaussian 09, with ethyl groups $\left(-\mathrm{C}_{2} \mathrm{H}_{5}\right)$ applied to represent the alkyl group of $\mathrm{C}_{17} \mathrm{H}_{33} \mathrm{COO}-$ $\mathrm{C}_{18} \mathrm{H}_{35} \mathrm{NH}$-, $\mathrm{C}_{12} \mathrm{H}_{25} \mathrm{~S}$ - and $\mathrm{C}_{12} \mathrm{H}_{25} \mathrm{O}$-; no simplicity was applied for the phenyl group of $-\mathrm{PPh}_{2}$. Full geometry optimizations were carried out to locate all of the stationary points via a hybrid B3LYP functional method with the SDD basis set and the corresponding effective core potential for the $\mathrm{Cd}$, Se and Te atoms, and the allelectron $6-31++\mathrm{G}(\mathrm{d}, \mathrm{p})$ basis set for the other atoms of $\mathrm{C}, \mathrm{H}, \mathrm{O}, \mathrm{N}, \mathrm{P}$ and $\mathrm{S}$, namely B3LYP/6-31+ G(d, p), SDD. The use of effective core potential and allelectron basis was the same as before ${ }^{25}$. Systematic harmonic frequency calculations were performed to ensure that all the structures obtained are true minima on the potential energy surfaces. A polarized continuum model (PCMSMD) with dielectric constant $\varepsilon=2.0$ was utilized to simulate the solvent effect of ODE via a hybrid M06 functional method with the same basis sets as mentioned above by performing single-point calculation on the optimized structures at the B3LYP/6-31+ + G(d, p), SDD level, namely M06//B3LYP/6-31+ + G(d, p), SDD. The charges and dominant occupancies of natural bond orbitals have been analysed with the help of the natural bond orbital analysis.

Data availability. The authors declare that all relevant data supporting the findings of this study are available from the authors on request.

\section{References}

1. Reineke, S. Complementary LED technologies. Nat. Mater. 14, 459-462 (2015).

2. Editorial. Let there be light. Nat. Mater. 14, 453 (2015).

3. Fan, F., Turkdogan, S., Liu, Z., Shelhammer, D. \& Ning, C. Z. A monolithic white laser. Nat. Nanotechnol. 10, 796-803 (2015).

4. Tan, C. K. \& Tansu, N. Nanostructured lasers: electrons and holes get closer. Nat. Nanotechnol. 10, 107-109 (2015).

5. Lan, X., Masala, S. \& Sargent, E. H. Charge-extraction strategies for colloidal quantum dot photovoltaics. Nat. Mater. 13, 233-240 (2014). 
6. Chuang, C. H. M., Brown, P. R., Bulovic, V. \& Bawendi, M. G. Improved performance and stability in quantum dot solar cells through band alignment engineering. Nat. Mater. 13, 796-801 (2014).

7. Resch-Genger, U., Grabolle, M., Cavaliere-Jaricot, S., Nitschke, R. \& Nann, T. Quantum dots versus organic dyes as fluorescent labels. Nat. Methods 5, 763-775 (2008).

8. Yu, J. H. et al. High-resolution three-photon biomedical imaging using doped ZnS nanocrystals. Nat. Mater. 13, 359-366 (2014).

9. Ming, K. et al. Integrated quantum dot barcode smartphone optical device for wireless multiplexed diagnosis of infected patients. ACS Nano 9, 3060-3074 (2015).

10. Murray, C. B., Norris, D. J. \& Bawendi, M. G. Synthesis and characterization of nearly monodisperse $\mathrm{CdE}$ (E = sulfur, selenium, tellurium) semiconductor nanocrystallites. J. Am. Chem. Soc. 115, 8706-8715 (1993).

11. Peng, Z. A. \& Peng, X. Formation of high-quality CdTe, CdSe, and CdS nanocrystals using CdO as precursor. J. Am. Chem. Soc. 123, 183-184 (2001).

12. Yang, Y. A., Wu, H., Williams, K. R. \& Cao, Y. C. Synthesis of CdSe and CdTe nanocrystals without precursor injection. Angew. Chem. Int. Ed. 44, 6712-6715 (2005).

13. Steckel, J. S., Yen, B. K. H., Oertel, D. C. \& Bawendi, M. G. On the mechanism of lead chalcogenide nanocrystal formation. J. Am. Chem. Soc. 128, 13032-13033 (2006)

14. Joo, J. et al. A reduction pathway in the synthesis of PbSe nanocrystals quantum dots. J. Am. Chem. Soc. 131, 10620-10628 (2009).

15. Evans, C. M., Evans, M. E. \& Krauss, T. D. Mysteries of TOPSe revealed: insights into quantum dot nucleation. J. Am. Chem. Soc. 132, 10973-10975 (2010).

16. Cossairt, B. M. \& Owen, J. S. At the interface of small molecules and quantum dots. Chem. Mater. 23, 3114-3119 (2011).

17. Ouyang, J. et al. Low-temperature approach to high-yield and reproducible syntheses of high-quality small-sized PbSe colloidal nanocrystals for photovoltaic applications. ACS Appl. Mater. Interfaces 3, 553-565 (2011).

18. Yu, K., Ouyang, J. \& Leek, D. M. In-situ observation of nucleation and growth of PbSe magic-sized nanoclusters and regular nanocrystals. Small 7, 2250-2262 (2011).

19. Yu, K. et al. Highly-photoluminescent ZnSe nanocrystals via a non-injectionbased approach with precursor reactivity elevated by a secondary phosphine. Chem. Commun. 47, 8811-8813 (2011).

20. Wang, F. \& Buhro, W. R. Morphology control of cadmium selenide nanocrystals: insights into the roles of di- $n$-octylphosphine oxide (DOPO) and di-n-octylphosphinic acid (DOPA). J. Am. Chem. Soc. 134, 5369-5380 (2012).

21. $\mathrm{Yu}, \mathrm{K}$. et al. Ultraviolet $\mathrm{ZnSe}_{1-x} \mathrm{~S}_{x}$ gradiently-alloyed nanocrystals via a noninjection approach. ACS Appl. Mater. Interfaces 4, 4302-4311 (2012).

22. Yu, K. et al. Low-temperature approach to highly emissive copper indium sulfide colloidal nanocrystals and their bioimaging applications. ACS Appl. Mater. Interfaces 5, 2870-2880 (2013).

23. Yu, K. et al. Effect of tertiary and secondary phosphines on low-temperature formation of quantum dots. Angew. Chem. Int. Ed. 52, 4823-4828 (2013).

24. Yu, K. et al. The formation mechanism of binary semiconductor nanomaterials shared by single-source and dual-source precursor approaches at ambient temperature. Angew. Chem. Int. Ed. 52, 11034-11039 (2013).

25. Yu, K. et al. Mechanistic study of the role of primary amines in precursor conversions to semiconductor nanocrystals at low temperature. Angew. Chem. Int. Ed. 53, 6896-6904 (2014)

26. Li, L. S., Pradhan, N., Wang, Y. \& Peng, X. High quality ZnSe and ZnS nanocrystals formed by activating carboxylate precursors. Nano Lett. 4, 2261-2264 (2004)

27. Xu, S., Kumar, S. \& Nann, T. Rapid synthesis of high-quality InP nanocrystals. J. Am. Chem. Soc. 128, 1054-1055 (2006).

28. Allen, P. M., Walker, B. J. \& Bawendi, M. G. Mechanistic insights into the formation of InP quantum dots. Angew. Chem. Int. Ed. 49, 760-762 (2010).

29. Kruszynska, M., Borchert, H., Parisi, J. \& Kolny-Olesiak, J. Synthesis and shape control of CuInS 2 nanoparticles. J. Am. Chem. Soc. 132, 15976-15986 (2010).

30. Meinardi, F. et al. Highly efficient large-area colourless luminescent solar concentrators using heavy-metal-free colloidal quantum dots. Nat. Nanotechnol. 10, 878-885 (2015).

31. Li, L. et al. Efficient synthesis of highly luminescent copper indium sulfidebased core/shell nanocrystals with surprisingly long-lived emission. J. Am. Chem. Soc. 133, 1176-1179 (2011).

32. Liu, H., Owen, J. S. \& Alivisatos, A. P. Mechanistic study of precursor evolution in colloidal group II-VI semiconductor nanocrystal synthesis. J. Am. Chem. Soc. 129, 305-312 (2007).

33. Owen, J. S., Chan, E. M., Liu, H. \& Alivisatos, A. P. Precursor conversion kinetics and the nucleation of cadmium selenide nanocrystals. J. Am. Chem. Soc. 132, 18206-18213 (2010)
34. Garcia-Rodriguez, R. \& Liu, H. Mechanistic study of the synthesis of CdSe nanocrystals: release of selenium. J. Am. Chem. Soc. 134, 1400-1403 (2012)

35. Garcia-Rodriguez, R. \& Liu, H. Mechanistic insights into the role of alkylamine in the synthesis of CdSe nanocrystals. J. Am. Chem. Soc. 136, 1968-1975 (2014).

36. Hendricks, M. P., Cossairt, B. M. \& Owen, J. S. The importance of nanocrystal precursor conversion kinetics: mechanism of the reaction between cadmium carboxylate and cadmium bis(diphenyldithiophosphinate). ACS Nano 6, 10054-10062 (2012).

37. Hendricks, M. P., Campos, M. P., Cleveland, G. T., Plante, J. L. \& Owen, J. S. A tunable library of substituted thiourea precursors to metal sulfide nanocrystals. Science 348, 1226-1230 (2015).

38. Zhang, J. et al. Bright gradient-alloyed $\mathrm{CdSe}_{\mathrm{x}} \mathrm{S}_{1-\mathrm{x}}$ quantum dots exhibiting cyan-blue emission. Chem. Mater. 28, 618-625 (2016).

39. Reed, A. E., Curtiss, L. A. \& Weinhold, F. Intermolecular interactions from a natural bond orbital, donor-acceptor viewpoint. Chem. Rev. 88, 899-926 (1988).

40. Becke, A. D. Density-functional thermochemistry. III. the role of exact exchange. J. Chem. Phys. 98, 5648-5652 (1993).

41. Vajda, S. et al. Subnanometre platinum clusters as highly active and selective catalysts for the oxidative dehydrogenation of propane. Nat. Mater. 8, 213-216 (2009).

42. Kazemi, M. \& Aqvist, J. Chemical reaction mechanisms in solution from brute force computational Arrhenius plots. Nat. Commun. 6, 7293 (2015).

43. Sharma, S., Sivalingam, K., Neese, F. \& Chan, G. K. L. Low-energy spectrum of iron-sulfur clusters directly from many-particle quantum mechanics. Nat. Chem. 6, 927-933 (2014).

44. Khusnutdinova, J. R. \& Milstein, D. Metal-ligand cooperation. Angew. Chem. Int. Ed. 54, 12236-12273 (2015).

45. Wang, Y., He, J., Liu, C., Chong, W. H. \& Chen, H. Thermodynamics versus kinetics in nanosynthesis. Angew. Chem. Int. Ed. 54, 2022-2051 (2015).

46. Lencer, D. et al. A map for phase-change materials. Nat. Mater. 7, 972-977 (2008).

47. Polking, M. J. et al. Ferroelectric order in individual nanometer-scale crystals. Nat. Mater. 11, 700-709 (2012).

48. Chen, O. et al. Compact high-quality CdSe-CdS core-shell nanocrystals with narrow emission linewidths and suppressed blinking. Nat. Mater. 12, 445-451 (2013).

49. Miszta, K. et al. Selective cation exchange in the core region of $\mathrm{Cu}_{2-x} \mathrm{Se} / \mathrm{Cu}_{2-x} \mathrm{~S}$ core/shell nanocrystals. J. Am. Chem. Soc. 137, 12195-12198 (2015).

50. Cooper, J. K., Gul, S., Lindley, S. A., Yano, J. \& Zhang, J. Z. Tunable photoluminescent core/shell $\mathrm{Cu}^{+}$doped $\mathrm{ZnSe} / \mathrm{ZnS}$ quantum dots codoped with $\mathrm{Al}^{3+}, \mathrm{Ga}^{3+}$, or $\mathrm{In}^{3+}$. ACS Appl. Mater. Interfaces 7, 1005-10066 (2015).

51. Yu, J. H. et al. Giant Zeeman splitting in nucleation-controlled doped CdSe: $\mathrm{Mn}^{2+}$ quantum nanoribbons. Nat. Mater. 9, 47-53 (2010).

52. Yang, J. et al. Route to the smallest doped semiconductor: $\mathrm{Mn}^{2+}$-doped (CdSe) ${ }_{13}$ clusters. J. Am. Chem. Soc. 137, 12776-12779 (2015).

53. Weissleder, R., Nahrendorf, M. \& Pittet, M. J. Imaging macrophages with nanoparticles. Nat. Mater. 13, 125-138 (2014).

54. Kovalenko, M. V. et al. Prospects of nanoscience with nanocrystals. ACS Nano 9, 1012-1057 (2015)

55. Curran, D. P. Free at last. Nat. Chem. 4, 958-958 (2012).

56. Cui, J. et al. Direct probe of spectral inhomogeneity reveals synthetic tunability of single-nanocrystal spectral linewidths. Nat. Chem. 5, 602-606 (2013).

57. Bao, J. \& Bawendi, M. G. A colloidal quantum dot spectrometer. Nature 523, 67-70 (2015)

\section{Acknowledgements}

We Dr Keith U. Ingold for his support and beneficial discussions, Dr Frank S. Riehle for invaluable discussions, Dr X. Wu for transmission electron microscopy and Dr M. Yang and Dr X. Wang for discussions on the DFT. Q.Y.C. thanks National Research Council of Canada's summer student programme. K.Y. thanks National Natural Science Foundation of China (NSFC) 21573155 and the Fundamental Research Funds for the Central Universities SCU2015A002.

\section{Author contributions}

K.Y. designed and directed this study. H.Y. designed and analysed the computational results. X.L. carried out NMR. T.Q. performed computation. Q.Y.C. and E.J.C.H. carried out in situ absorption monitoring. K.Y. and D.M.W. wrote the manuscript, with the help of the co-authors. All authors analysed and discussed the results and commented on the manuscript.

\section{Additional information}

Supplementary Information accompanies this paper at http://www.nature.com/ naturecommunications 
Competing financial interests: The authors declare no competing financial interests.

Reprints and permission information is available online at http://npg.nature.com/ reprintsandpermissions/

How to cite this article: Yu, K. et al. General low-temperature reaction pathway from precursors to monomers before nucleation of compound semiconductor nanocrystals. Nat. Commun. 7:12223 doi: 10.1038/ncomms12223 (2016). (c) (i) This work is licensed under a Creative Commons Attribution 4.0 International License. The images or other third party material in this article are included in the article's Creative Commons license, unless indicated otherwise in the credit line; if the material is not included under the Creative Commons license, users will need to obtain permission from the license holder to reproduce the material. To view a copy of this license, visit http://creativecommons.org/licenses/by/4.0/

(C) The Author(s) 2016 